University of South Florida

DIGITAL COMMONS

Digital Commons @ University of

@ UNIVERSITY OF SOUTH FLORIDA

South Florida

$4-15-1994$

\title{
A Numerical Analysis of Shipboard and Coastal Zone Color Scanner Time Series of New Production Within Gulf Stream Cyclonic Eddies in the South Atlantic Bight
}

\author{
J. Raymond Pribble \\ University of South Florida \\ John J. Walsh \\ University of South Florida, jwalsh@usf.edu \\ Dwight A. Dieterle \\ University of South Florida \\ Frank E. Muller-Karger \\ University of South Florida, carib@usf.edu
}

Follow this and additional works at: https://digitalcommons.usf.edu/msc_facpub

Part of the Marine Biology Commons

\section{Scholar Commons Citation}

Pribble, J. Raymond; Walsh, John J.; Dieterle, Dwight A.; and Muller-Karger, Frank E., "A Numerical Analysis of Shipboard and Coastal Zone Color Scanner Time Series of New Production Within Gulf Stream Cyclonic Eddies in the South Atlantic Bight" (1994). Marine Science Faculty Publications. 66.

https://digitalcommons.usf.edu/msc_facpub/66

This Article is brought to you for free and open access by the College of Marine Science at Digital Commons @ University of South Florida. It has been accepted for inclusion in Marine Science Faculty Publications by an authorized administrator of Digital Commons @ University of South Florida. For more information, please contact digitalcommons@usf.edu. 


\title{
A numerical analysis of shipboard and coastal zone color scanner time series of new production within Gulf Stream cyclonic eddies in the South Atlantic Bight
}

\author{
J. Raymond Pribble, John J. Walsh, and Dwight A. Dieterle \\ Department of Marine Science, University of South Florida, St. Petersburg
}

\author{
Frank E. Müller-Karger \\ NASA Headquarters, Washington, D. C.
}

\begin{abstract}
Eddy-induced upwelling occurs along the western edge of the Gulf Stream between Cape Canaveral, Florida, and Cape Hatteras, North Carolina, in the South Atlantic Bight (SAB). Coastal zone color scanner images of $1-\mathrm{km}$ resolution spanning the period April 13-21, 1979, were processed to examine these eddy features in relation to concurrent shipboard and current/temperature measurements at moored arrays. A quasi-one-dimensional $(z)$, time-dependent biological model, using only nitrate as a nutrient source, has been combined with a three-dimensional physical model in an attempt to replicate the observed phytoplankton field at the northward edge of an eddy. The model is applicable only to the SAB south of the Charleston Bump, at $\sim 31.5^{\circ} \mathrm{N}$, since no feature analogous to the bump exists in the model bathymetry. The modeled chlorophyll, nitrate, and primary production fields of the euphotic zone are very similar to those obtained from the satellite and shipboard data at the leading edges of the observed eddies south of the Charleston Bump. The horizontal and vertical simulated fluxes of nitrate and chlorophyll show that only $\sim 10 \%$ of the upwelled nitrate is utilized by the phytoplankton of the modeled grid box on the northern edge of the cyclone, while $\sim 75 \%$ is lost horizontally, with the remainder still in the euphotic zone after the 10-day period of the model. Loss of chlorophyll due to sinking is very small in this strong upwelling region of the cyclone. The model is relatively insensitive to variations in the sinking parameterization and the external nitrate and chlorophyll fields but is very sensitive to a reduction of the maximum potential growth rate to half that measured. Given the success of this model in simulating the new production of the selected upwelling region, other upwelling regions for which measurements or successful models of physical and biological quantities and rates exist could be modeled similarly.
\end{abstract}

\section{Introduction}

The South Atlantic Bight (SAB) extends from Cape Canaveral, Florida $\left(\sim 28.5^{\circ} \mathrm{N}\right)$, to Cape Hatteras, North Carolina $\left(35^{\circ} \mathrm{N}\right)$. In the southern part of this region $\left(28.5^{\circ}-\right.$ $31.5^{\circ} \mathrm{N}$ ), the Gulf Stream's western edge tends to remain within $15 \mathrm{~km}$ of the shelf break [Bane and Brooks, 1979]. Here, eddy-induced upwelling occurs close to the continental shelf break [Lee et al., 1985]. A topographical irregularity at $\sim 31.5^{\circ} \mathrm{N}$, the Charleston Bump, may force the Gulf Stream front as much as $100 \mathrm{~km}$ offshore, resulting in enlarged eddy events in the northern part of the SAB [Legeckis, 1979; Bane and Brooks, 1979].

Cyclonic eddy events in the southern part of the SAB result in cold, nutrient-rich water being raised from under the Gulf Stream into the euphotic zone on the western edge of the stream [Atkinson, 1985]. The eddies have a temporal scale of 1-3 weeks [Lee and Mayer, 1977] as they move northward at 30-50 $\mathrm{km} \mathrm{d}^{-1}$ [Vukovich et al., 1979; Legeckis,

Copyright 1994 by the American Geophysical Union.

Paper number 93JC02907. 0148-0227/94/93JC-02907\$05.00
1979; Lee et al., 1981; Zantopp et al., 1987] with the Gulf Stream; this period is long enough that phytoplankton can utilize some or all of the high levels of upwelled nutrients, 10-15 $\mu M \mathrm{NO}_{3}$ at the bottom of the euphotic zone [Lee et al., 1985; Atkinson, 1985]. Upwelling velocities associated with these eddies are estimated at around $10^{-2} \mathrm{~cm} \mathrm{~s}^{-1}$ [Lee et al., 1985], so that nitrate is continuously pumped into the euphotic zone, resulting in high primary productivity.

Yoder et al. [1983] determined an average primary productivity for April 22-30, 1979, over the outer shelf of $\sim 2.7 \mathrm{~g} \mathrm{C}$ $\mathrm{m}^{-2} \mathrm{~d}^{-1}$ at $30.5^{\circ} \mathrm{N}$. This time span included the periods preceding, during, and following the passage of two eddies [Yoder et al., 1983]. Surface chlorophyll concentrations were 10-20 times those in surrounding Gulf Stream and shelf waters unimpacted by eddy-induced upwelling [Yoder et al., 1981]. An annual outer shelf primary productivity estimate is $\sim 360 \mathrm{~g} \mathrm{C} \mathrm{m}^{-2}$ [Yoder, 1985], given the presence of eddies $\sim 50 \%$ of the time and $\sim 2 \mathrm{~g} \mathrm{C} \mathrm{m}^{-2} \mathrm{~d}^{-1}$ primary productivity within the eddies, a value obtained by averaging 1979 and 1980 data.

The nitrate upwelled within these eddies results in "new" production, which is defined as the amount of primary 


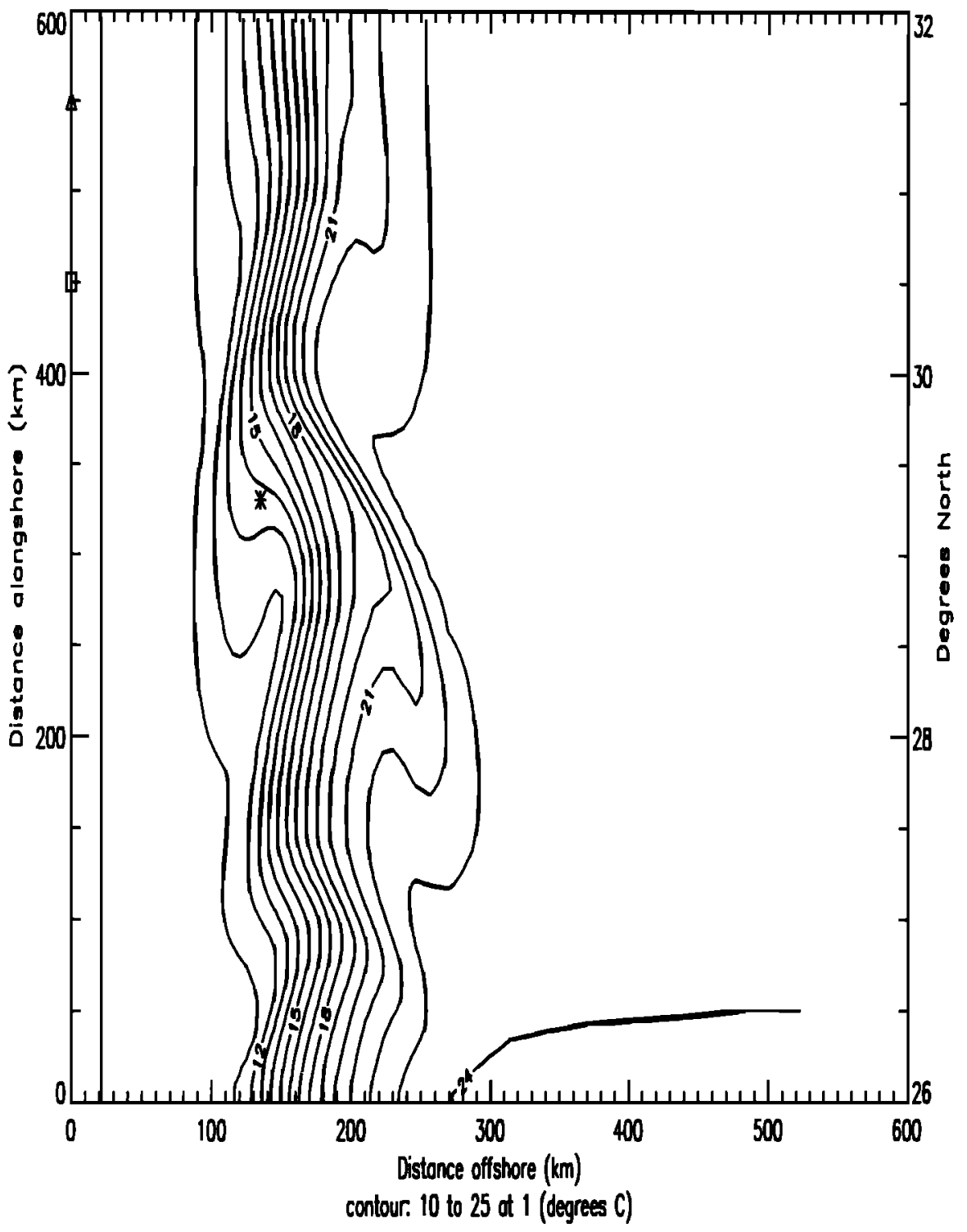

Figure 1. Surface model temperature (degrees Celsius) on simulated model day 15 of the physical model over model domain. The asterisk marks the center of the grid column of the biological model, at $\sim 29.3^{\circ} \mathrm{N}$ and $\sim 134.5 \mathrm{~km}$ offshore. The latitude of primary production stations is marked by an open square at 450 $\mathrm{km}$; that of moored arrays is marked by an open triangle at $550 \mathrm{~km}$.

production that is derived from "new" nitrogen (imported nitrate). Estimates of new production as a fraction of total production over the area affected by these eddies range from $>50 \%$ to $>70 \%$ [Yoder et al., 1983; Lee et al., 1991]. However, since these values were obtained at stationary locations as the eddies passed [Yoder et al., 1983] and from estimates of nitrate usage within the entire SAB [Lee et al., 1991], these values are probably lower than the new production actually occurring within the eddies.

The event time scale of the eddies may preclude the development of higher trophic levels sufficient to impact the phytoplankton biomass and productivity [Atkinson et al., 1978; Heinbokel, 1978; Verity, 1985; Deibel, 1982]. Therefore an $f$ ratio (ratio of new production to total production) of $>0.75$ would not be unreasonable within an eddy, while early stages of the eddies may have $f$ ratios approaching 1 , compared with 0.2 for a warm-core ring [Franks et al., 1986].
To ascertain the magnitude of new production within an eddy, a quasi-one-dimensional ( $z$ ) time-dependent biological model is coupled with a three-dimensional $(x, y, z)$ physical model of the region. The biological domain is initialized and run with values from a single snapshot of the physical model, so that the physical flow field used in the model is time invariant. These values are taken from day 15 of the physical model, after the modeled wave developed, at the $y$ coordinate corresponding to $\sim 29.3^{\circ} \mathrm{N}$ (Figure 1). The vertical column modeled is chosen to correspond to the point in the physical model which has the strongest upwelling velocities. New production is tracked as a function of time within this column, so that conclusions can be drawn as to the rates of new production and the resultant chlorophyll field present at different stages of an eddy within the SAB. To check on the accuracy of this coupled model, data from a cruise in April 1979 [Yoder et al., 1981] and coastal zone color scanner 
(CZCS) satellite images from April 13-21, 1979, are used. Along with the satellite images, data from moored arrays are used to estimate the speeds and alongshore extents of the measured eddies, forming a database of a series of eddies (see Figure 1 for latitude of moored arrays in relation to model domain).

Previously, a biological model had been coupled to interpolated velocity and temperature fields within the southern SAB to study both bottom intrusions and eddy events [Hofmann, 1988]. The interpolated fields, however, were at a nominal depth of $37 \mathrm{~m}$, so that the model was two dimensional $(x, y)$, and the model domain for the eddy study was bounded to the north and south by $\sim 31^{\circ}$ and $\sim 29^{\circ} \mathrm{N}$, respectively; the longitudinal boundaries were $\sim 80.5^{\circ}$ and $\sim 80^{\circ} \mathrm{W}$, or approximately a $200 \mathrm{~km}$ by $45 \mathrm{~km}$ rectangle [Ishizaka and Hofmann, 1988]. This two-dimensional study resolved the northward movement of eddy events through the eastern side of the model domain along with the biological properties associated with the eddies, allowing estimates of horizontal nitrate and chlorophyll fluxes through the model domain [Hofmann, 1988].

The biological model coupled with the interpolated flow fields utilized a multiplicative function of light and nutrients to determine phytoplankton growth and tracked two size classes of phytoplankton as well as various life stages of copepods [Hofmann and Ambler, 1988]. The combination of the biological model and the interpolated velocity and temperature fields reproduced measured patterns of chlorophyll reasonably well, though the magnitudes of the modeled single-level values and the measured depth-integrated values differed [Hofmann, 1988]. Extension of this model to three dimensions was not feasible owing to the scarcity of current meter data at other depths [Ishizaka and Hofmann, 1988], and so the model could not simulate vertical temperature, chlorophyll, or nitrate profiles for comparison with measured profiles within eddy events [Yoder et al., 1983].

A similar model, utilizing an interpolated flow field at $17 \mathrm{~m}$ and calculated from meters located at $17 \mathrm{~m}$ and the other meters nearest the 17-m depth, was compared with CZCS images for the same model domain for the spring of 1980 [Ishizaka, 1990a, b]. The model was improved by readjusting the horizontal chlorophyll field with information garnered from the images after a relationship was made between the chlorophyll field at $17 \mathrm{~m}$ and the CZCS image [Ishizaka, $1990 \mathrm{c}$ ], which was assumed to sense only the top $10 \mathrm{~m}$ [Ishizaka, 1990a]. Like the previously discussed model, however, this model had no vertical dimension and was subject to similar constraints when comparisons with measured data were made.

Other recent models utilizing simple coupled physical/ biological models are those of Franks et al. [1986] and Marra and Ho [1993]. The Franks et al. [1986] study sought to determine the cause of the high phytoplankton biomass observed in Gulf Stream warm-core rings utilizing a twodimensional (vertical and radial) time-dependent biological model incorporating phytoplankton, nitrogen, and zooplankton. The Marra and Ho [1993] study examined the spring phytoplankton bloom observed in the North Atlantic with a one-dimensional time-dependent biological model based on the biochemical interactions of the Franks et al. [1986] biological model.

The warm-core ring study [Franks et al., 1986] depended on the relaxation of the depressed warm-core pycnocline to the same level as in the surrounding waters to provide nutrients to the euphotic zone over a period of 60 days, with a vertical velocity of $\sim 1 \mathrm{~m} \mathrm{~d}^{-1}$, or $\sim 10^{-3} \mathrm{~cm} \mathrm{~s}^{-1}$. The light field had no diel variation, and phytoplankton loss terms were due only to death and grazing, with dead phytoplankton and zooplankton and the unassimilated fraction of ingested phytoplankton returned to the nutrient pool: growth rates decreased exponentially with depth in the same manner as the light field [Franks et al., 1986].

The North Atlantic spring bloom study [Marra and $\mathrm{Ho}$, 1993] used a one-dimensional (vertical) mixed-layer model, reproducing the increasing stratification observed over a 2-week period to simulate the observed phytoplankton distribution over time. Measured daily photosynthetically active radiation (PAR) values were used to calculate hourly PAR, with nutrient levels within the phytoplankton (cell quota model) in conjunction with the Michaelis-Menten formulation for nutrient uptake determining growth in a multiplicative function model with light [Marra and $\mathrm{Ho}$, 1993].

\section{Methods \\ Satellite Images}

A series of CZCS images depicting the probable evolution of eddies through the SAB was selected for analysis. Images were initially selected for further processing using a browse facility, which enabled the user to select images of interest by examining them on a video display. These selected images spanned the period April 13-21, 1979, and showed the chlorophyll-associated manifestation of several cyclonic eddies. The steps followed to arrive at the final processed color images are given by Müller-Karger et al. [1989].

The images were navigated so that the array elements were placed at appropriate longitudes and latitudes. Next, the chlorophyll channel was extracted, and gray values (colors) were assigned to pigment concentration values within the arrayed image data. A remapping procedure realigned the pigment data into a cylindrical equidistant projection over the SAB region, and a land mask was included. These processing steps were done for both $4-\mathrm{km}$ and $1-\mathrm{km}$-resolution images of the region. The $1-\mathrm{km}-$ resolution images not only allowed a much better view of the effect of physical processes acting on the phytoplankton assemblages but also improved estimations of areal extent of ocean color and movements associated with the color patches over those obtained from the 4-km-resolution images.

\section{Physical Model}

The circulation model employed is the three-dimensional, time-dependent primitive equation model of Bryan [1969]. This model provides a numerical solution to the NavierStokes equations for variable bottom topography and arbitrary coastline. The Boussinesq and hydrostatic approximations are employed; the Boussinesq approximation is used to neglect the spatial variability in density except in those terms in which it is multiplied by gravity, and the hydrostatic approximation is used to reduce the vertical component of the equation of motion to the hydrostatic relationship wherein the net pressure force in the vertical exactly balances the force of gravity. A "rigid lid" approximation is also used, and vertical displacements of the ocean surface 
are not allowed. This approximation removes that component of the solution due to fast external gravity waves, permitting a much larger time step in the model. The computer code for this model is documented by Cox [1984].

The formulation of the problem is similar to those of Luther and Bane [1985] and Mellor et al. [1986]. A slope region bordering a straight coastline is considered, with the depth of the bottom $D$ (meters) a function only of offshore distance $x$ (kilometers), given by

$$
D=100+950[1+\tanh ([x-145] / 40)] .
$$

This expression defines the shallowest region of the model, at $x=0$, to have a depth of $\sim 101 \mathrm{~m}$. Latitudinal dependence of the Coriolis parameter is ignored, and a value appropriate for $31^{\circ} \mathrm{N}$ is used. Density is assumed to be a function of temperature alone, i.e.,

$$
\rho=\rho_{0}(1-\alpha T),
$$

where $T$ is temperature in degrees Celsius, $\alpha\left(=1.15 \times 10^{-4}\right.$ ${ }^{\circ} \mathrm{C}^{-1}$ ) is the thermal expansivity of seawater, and $\rho_{0}=1.0 \mathrm{~g}$ $\mathrm{cm}^{-3}$.

The model Gulf Stream is assumed initially to be in steady state and in geostrophic balance with the temperature field, given by

$$
T=T_{0}-\Delta T\left[3-2\left(\delta x_{b}+1\right) e^{-\delta x}\right](z \varepsilon-1) e^{2 \varepsilon z},
$$

which defines the temperature field at all depths [Luther and Bane, 1985]. Here $T_{0}, \Delta T, \delta$, and $\varepsilon$ are set at $4^{\circ} \mathrm{C}, 7^{\circ} \mathrm{C}$, $3.0 \times 10^{-5} \mathrm{~m}^{-1}$, and $1.3 \times 10^{-3} \mathrm{~m}^{-1}$, respectively; and $x_{b}$ is equal to $x-x_{f}$, where $x_{f}=100 \mathrm{~km}$ is the position of the Gulf Stream front relative to the coast, and $x_{b}$ is either zero or a positive quantity. This expression was derived to approximate the Gulf Stream with appropriate parameter choice [Orlanski and Cox, 1973]. An expression for the alongshore component of the surface velocity, using the thermal wind relationship, is given as

$$
V=g \alpha(\Delta T / f \varepsilon) \delta^{2} x_{b} \exp \left(-\delta x_{b}\right)(3 / 2),
$$

where $f$ is the Coriolis parameter, and $g$ is the acceleration due to gravity. As in Luther and Bane [1985], the constants in (2) and (3) were chosen to approximate the vertical and horizontal shears and transport of the Gulf Stream along the southeastern U.S. continental margin. The initial subsurface flow field is in geostrophic equilibrium with the temperature field, the alongshore velocities changing with the temperature field as the model progresses. The resulting initial velocity distribution produces a total northward transport of approximately $52 \mathrm{~Sv}$ through the model domain, with maximum velocities within the modeled Gulf Stream of $\sim 130 \mathrm{~cm}$ $\mathbf{s}^{-1}$. This is approximately equivalent to the velocity measured by Richardson et al. [1969] at $\sim 100 \mathrm{~m}$ at $32.4^{\circ} \mathrm{N}$, where the total transport was $\sim 53 \mathrm{~Sv}$.

Solid wall boundaries exist along the coast and against the slope. The shelf, with a minimum depth of $101 \mathrm{~m}$ at the coast, is thus comparable to the shelf break. At these boundaries a no-slip condition is prescribed for the velocity components, and the condition of a null normal derivative is used for temperature. Null vertical derivatives are prescribed for temperature as well as velocity at the upper and lower boundaries. To simplify the problem, the flow far offshore is assumed to be negligible, and a no-slip condition is used. This (artificial) boundary is sufficiently removed from the axis of the Gulf Stream so as to not influence the solution within the interior of the domain.

Open boundaries occur across the southern and northern regions of the physical model as well as offshore. At the southern inflow boundary, the depth-averaged, external mode flow normal to the boundary is held fixed in time, and internal mode velocities are calculated by the Sommerfeld radiation condition [Orlanski, 1976]. The tangential velocity component along the inflow boundary is set to zero. Along the outflow boundary a Sommerfeld radiation condition is used for temperature, stream function, and the normal velocity component. For the tangential component, the alongshore derivative is set at zero.

Variable grid spacing is used in the offshore direction, providing a minimum grid increment of $5 \mathrm{~km}$ at the point where the bathymetric gradient is steepest to approximately $45 \mathrm{~km}$ at $x=525 \mathrm{~km}$, the offshore extent of the physical model domain. A uniform increment of $5 \mathrm{~km}$ is used in the alongshore direction over a $600-\mathrm{km}$ range. A logarithmically increasing grid spacing is used in the vertical, providing a spacing of $25 \mathrm{~m}$ near the surface to approximately $425 \mathrm{~m}$ at the bottom.

Horizontal diffusion is modeled using a standard horizontal Laplacian operator for both velocity and temperature. The horizontal eddy viscosity and diffusivity are specified as functions of the offshore grid increment, varying from 250 $\mathrm{m}^{2} \mathrm{~s}^{-1}$ for $5-\mathrm{km}$ grid spacing to $\sim 1045 \mathrm{~m}^{2} \mathrm{~s}^{-1}$ for $45-\mathrm{km}$ spacing. A constant $10 \mathrm{~cm}^{2} \mathrm{~s}^{-1}$ eddy coefficient is used for temperature and velocity in the vertical.

Following Mellor et al. [1986], perturbations in the flow were generated by a $25-\mathrm{km}$ offshore displacement of the temperature field along the southern inflow transect over a period of 4 days and were followed by a return of the temperature pattern to its original position over a period of another 4 days. This 8 -day oscillation is repeated for the duration of the integration.

By day 8 of the integration, a wave has developed on the shoreward side of the Gulf Stream front with an alongshore dimension of approximately $125 \mathrm{~km}$ and an across-shelf dimension of approximately $50 \mathrm{~km}$. This wave continues to develop and move northward at a speed of $20-25 \mathrm{~km} \mathrm{~d}^{-1}$, with upward vertical velocities of $2-4 \times 10^{-2} \mathrm{~cm} \mathrm{~s}^{-1}$ in advance of the wave and corresponding downward vertical velocities to the south of the wave trough (see Figure 2). The 20-25 $\mathrm{km} \mathrm{d}^{-1}$ propagation speed is much closer to that measured for the eddies studied in $1979\left(\sim 35 \mathrm{~km} \mathrm{~d}^{-1}\right.$ [Yoder et al., 1981]) than for those studied in $1980\left(\sim 47.5 \mathrm{~km} \mathrm{~d}^{-1}\right.$ [Lee et al., 1985]), so that we chose to attempt replication of the 1979 data.

The area in which the physical model predicts strongest upwelling velocities, as in Oey [1988] and Luther and Bane [1985], does not coincide with the areas of lowest temperature given by the physical model but leads the minimum surface temperature patch (Figure 1; compare with Figure 2). Luther and Bane [1985] showed that a cold dome forms between an upwelling center to the north and a downwelling center to the south, and the low-temperature signature is between these two regions. The cruise measurements found that the minimum temperature region corresponded to the highest chlorophyll biomass region [Yoder et al., 1981]. It should also be noted that the depth formulation does not include a Charleston Bump type feature. Because of this, the 


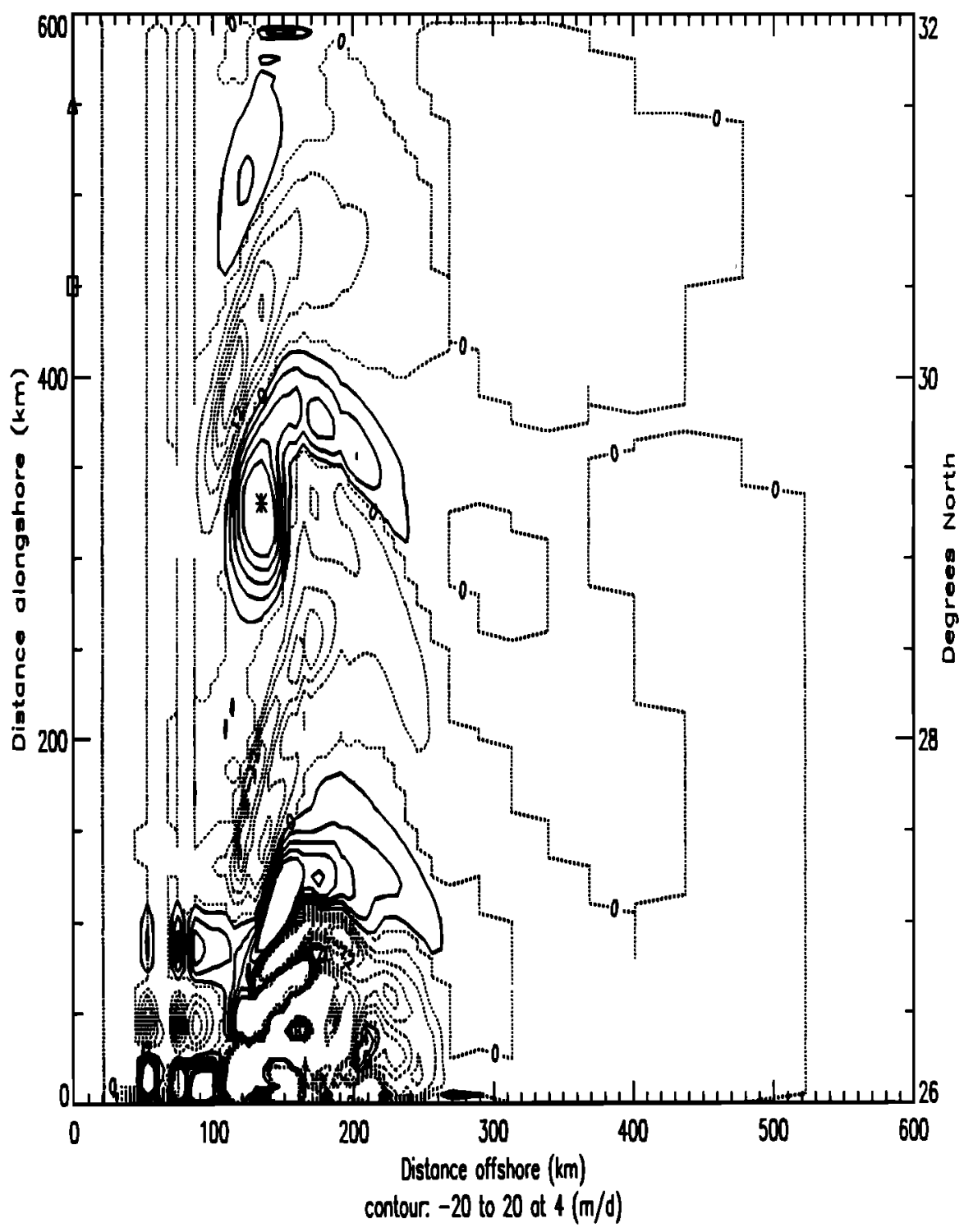

Figure 2. Model domain, southern SAB, with vertical velocity field (meters per day) at depth of 102.54 $\mathrm{m}$ on simulated day 15 of the physical model. Latitudes of primary production stations and moored arrays are marked as in Figure 1.

biological model is used only to the south of the area where the Charleston Bump may affect the Gulf Stream, at $\sim 31.5^{\circ} \mathrm{N}$.

\section{Biological Model}

The quasi-one-dimensional biological model is assumed to be located at the horizontal grid point in the simulated eddy where the modeled upwelling is strongest. In the vertical domain, $z$ and $w$ are positive upward, while $(x, u)$ and $(y, v)$ from the physical model are positive eastward and northward, respectively. The physical model provides the velocity field and the temperature field for input to the biological model after the waveform develops (see Figures 1 and 2) on day 15 of the physical model at the $y$ coordinate corresponding to $\sim 29.3^{\circ} \mathrm{N}$. These fields are not upgraded in time and space such that the biological model is subject to the same velocity field throughout the time integration. The initial temperature-derived nutrient field is acted upon only by these initial velocity fields, subsequent diffusion, and biological processes within the simulated water column.

The ecological context of the simulated vertical column, based on CZCS satellite images and shipboard measurements, is taken to be the phytoplankton population at the leading edge of the trough in the wavelike meander structure of the flow (see Figure 1) near the region where the warm filament bends around the cold dome. The modeled vertical column associated with this region is followed northward, with the nitrate and phytoplankton stocks within the column subject to the horizontal and vertical velocities given by the physical model (Figures 3 and 4) over a temporal period consistent with the observed persistence of an eddy in the southern region of the $\mathrm{SAB}$. This time period is taken to be 10 days, assuming that the eddies form at $\sim 28^{\circ} \mathrm{N}$; the model is applicable only to $\sim 31.5^{\circ} \mathrm{N}$; and the propagation speed of the eddies for 1979 was $\sim 35 \mathrm{~km} \mathrm{~d}^{-1}$ [Yoder et al., 1983]. 


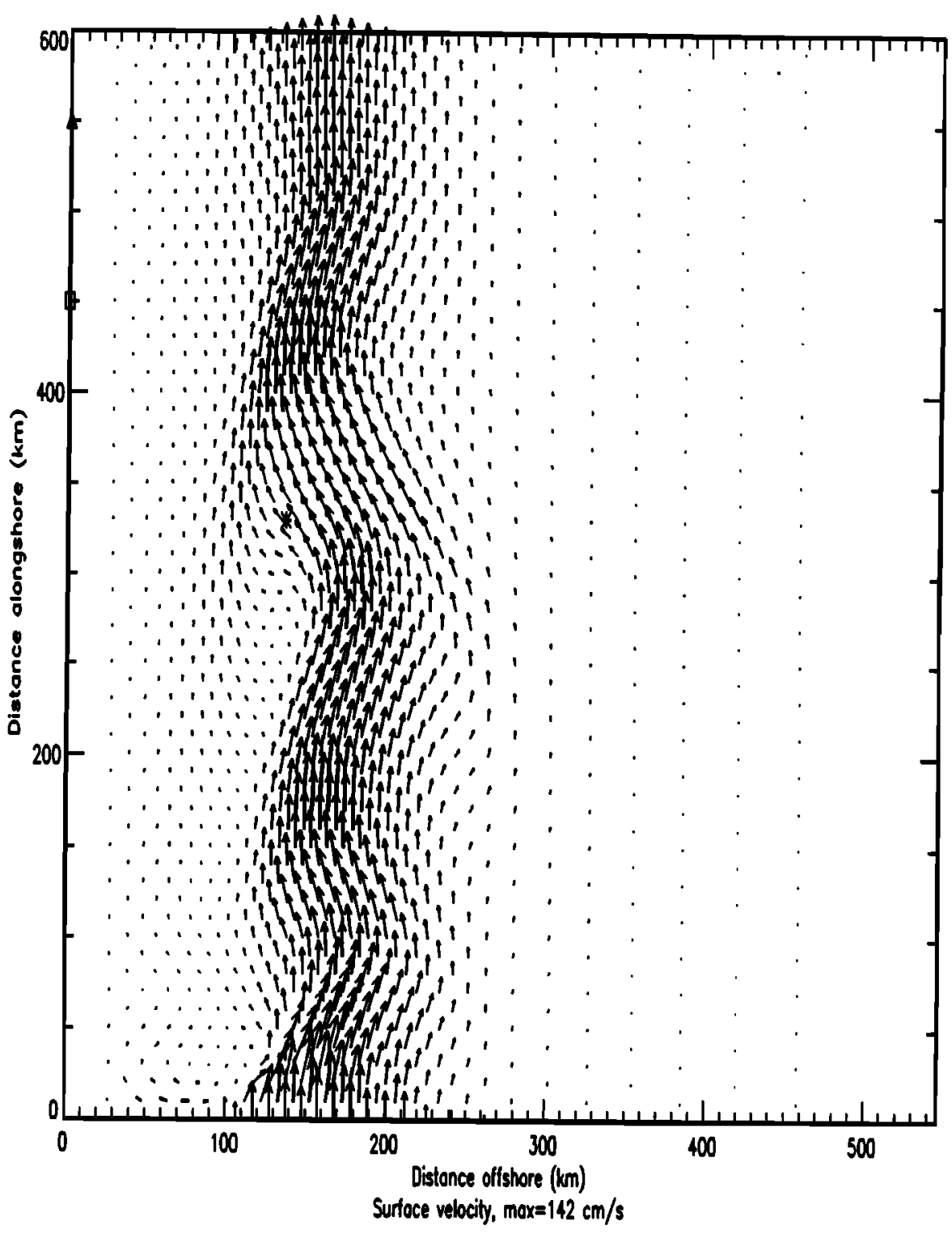

Figure 3. Surface model horizontal velocities over model domain, with center of biological model column marked with an asterisk, on day 15 of the physical model. Latitudes of primary production stations and moored arrays are marked as in Figure 1.

The physical model does not simulate nitrate fields, but temperature is one of the variables determined as a means of recreating the observed flow field [Richardson et al., 1969]. Given the temperature, nitrate concentrations in waters unexposed to biological activity can be calculated from the relationship found in upwelled North Atlantic Central Water on the SAB shelf,

$$
\mathrm{NO}_{3}=38.21-1.67 T\left({ }^{\circ} \mathrm{C}\right)
$$

[Atkinson et al., 1982, 1984]. This relationship was used by Hofmann [1988], and a similar temperature-nitrate relationship was used more recently by Sathyendranath et al. [1991] for Georges Bank. However, the physical model predicts temperatures in the euphotic zone approximately $10^{\circ} \mathrm{C}$ lower than those observed (compare Figures 5 and 6).

The initial temperature field was chosen to allow the velocity structure to approximate that measured off Cape
Fear, North Carolina [Luther and Bane, 1985; Richardson et al., 1969], at $32.4^{\circ} \mathrm{N}$. The total Gulf Stream transport at this latitude was $\sim 53 \mathrm{~Sv}$ [Richardson et al., 1969], an increase of $\sim 20 \mathrm{~Sv}$ over the transport through the Florida Straits [Richardson et al., 1969; Knauss, 1969] at $\sim 25.5^{\circ} \mathrm{N}$. Since the physical model has no lateral influx of water, the southern boundary must have the same transport as the northern boundary.

As a consequence of the $52 \mathrm{~Sv}$ at the southern boundary and of (4), the simulated temperature field is thus not representative of "real world" temperatures. The nitratetemperature relationship is therefore modified to

$$
\mathrm{NO}_{3}=28.21-1.67 T\left({ }^{\circ} \mathrm{C}\right) \text {. }
$$

This modification is used throughout the aphotic water column. This is done so that instead of simply specifying a constant aphotic zone nitrate boundary condition, the model 


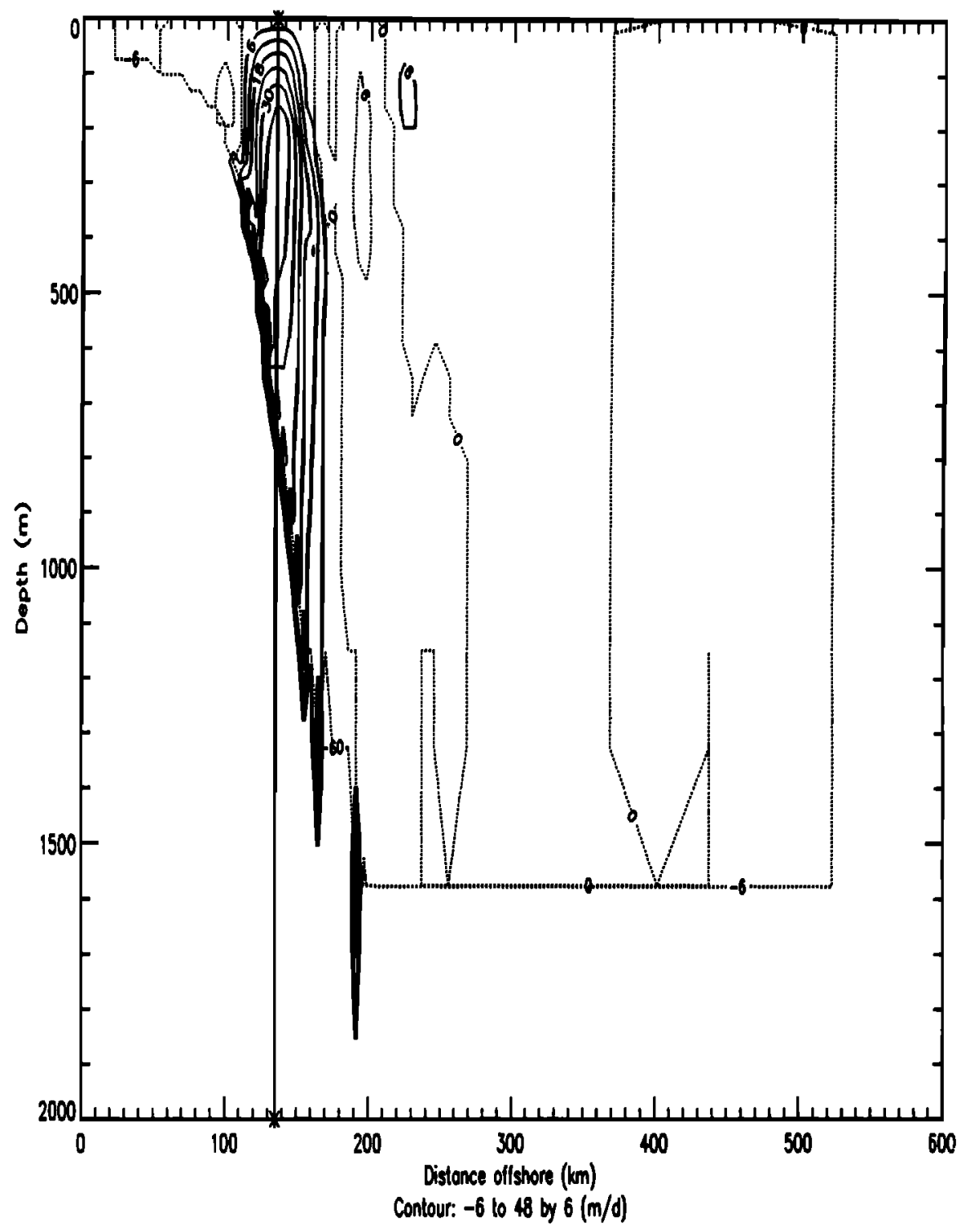

Figure 4. Physical model vertical velocity field (meters per day) at latitude where physical model values were chosen to run the biological model $\left(\sim 29.3^{\circ} \mathrm{N}\right)$, with the center of the biological model column at $\sim 134.5 \mathrm{~km}$ offshore marked by a vertical line at day 15 of the physical model.

more nearly replicates the upwelling of increasingly colder isotherms into the euphotic zone throughout the eddy lifetime.

Nitrate (micromolar) is the nutrient state variable described by

$\partial N / \partial t=-\partial(w N) / \partial z+\partial / \partial z\left(k_{z} \partial N / \partial z\right)-\mu P-H(N)$.

Similarly, the chlorophyll field, in terms of particulate nitrogen (micromolar) is described by

$$
\begin{aligned}
\partial P / \partial t=-\partial(w P) / \partial z+\partial / \partial z\left(k_{z} \partial P / \partial z\right) \\
\\
+\mu P-\partial\left(w_{s} P\right) / \partial z-H(P) .
\end{aligned}
$$

These two equations are solved explicitly. The first terms on the right-hand sides of both (7) and (8) are the advective terms, where $w$ is the vertical velocity and $N$ and $P$ are the nitrate and particulate nitrogen concentrations (in terms of micromoles $\mathbf{N}$ ), respectively. These advective equations are solved following the method of Smolarkiewicz [1983]. The second terms of the two equations are the diffusive terms, where $k_{z}$ is the vertical eddy diffusivity; these terms involve the flux formulation from the physical model, with $k_{z}=10.0$ $\mathrm{cm}^{2} \mathrm{~s}^{-1}$.

The third terms account for the growth of phytoplankton, which serves as a loss in the nitrate equation and an increase in the particulate nitrogen equation. The growth term $(\mu)$ in (7) and (8) is treated separately as a function of both light $\left(\mu_{l}\right)$ and nitrate $\left(\mu_{n}\right)$. To determine which growth rate is used, the two rates are compared, and the minimum rate is selected.

The growth rate is the most sensitive parameter of our analysis, as it is one of the most sensitive in the Marra and Ho [1993] study, and we chose a formulation which yields the largest growth rate at each time step to simulate succes- 


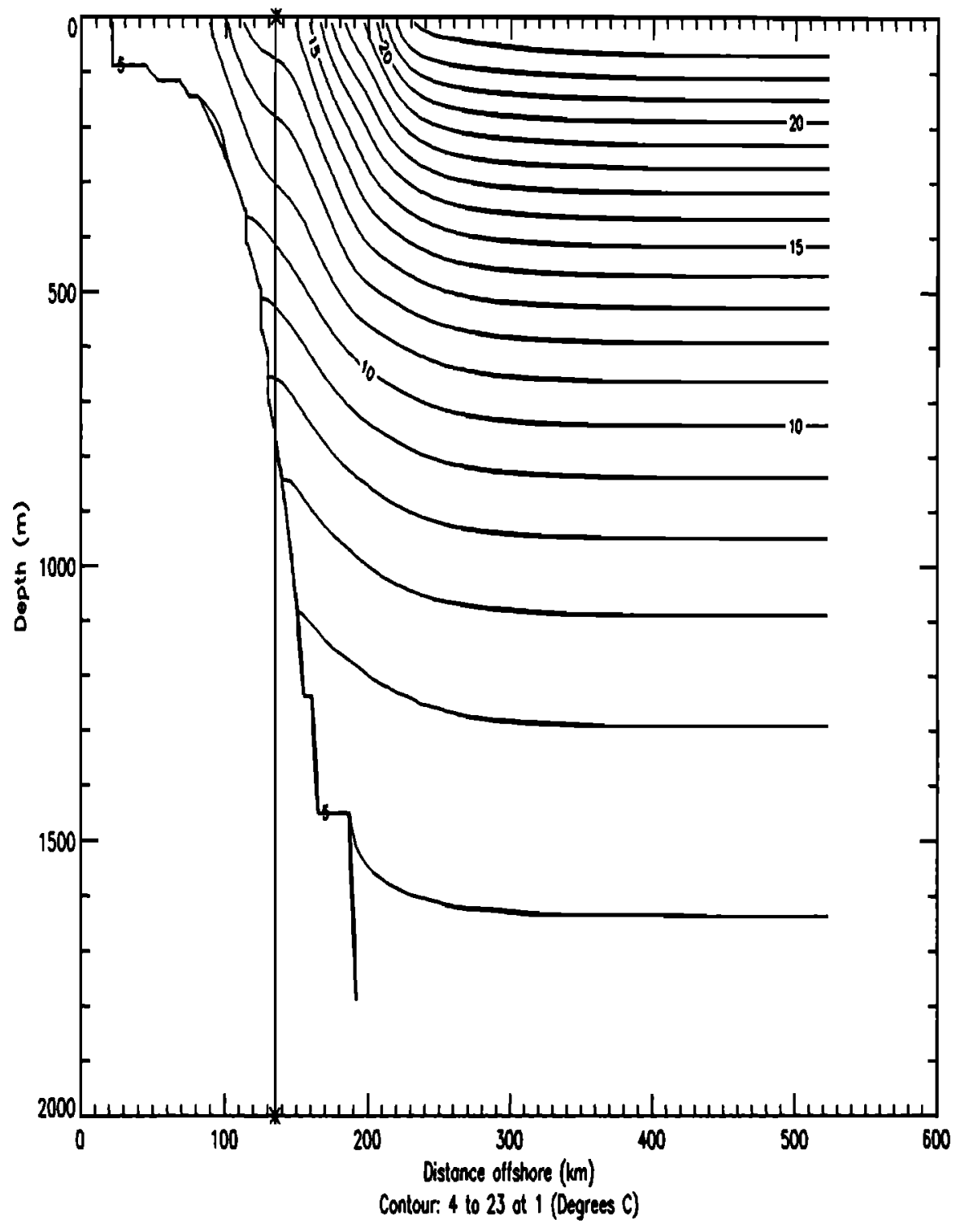

Figure 5. Model temperature field offshore at $\sim 29.3^{\circ} \mathrm{N}$, with the center of the biological model column at $\sim 134.5 \mathrm{~km}$ offshore marked by a vertical line at day 15 of the physical model.

sion of opportunistic species within the cyclonic eddy. This approach follows Liebig's [1847] original idea, further articulated by Blackman [1905], that the rate of a biological process depends upon the supply of a single limiting factor in contrast to being a multiplicative function of diverse factors [Goldman and Carpenter, 1974; Walsh et al., 1989; Gregg and Walsh, 1992]. Biological processes described by Blackman-type kinetics appear to be appropriate for single-species assemblages [Rhee and Gotham, 1981a, b; Tilman et al., 1981]. Since the model's phytoplankton are not differentiated into species groupings, we assume that the cyclone's algal population reflects the measured characteristics of diatoms [Yoder et al., 1981, 1983; Yoder, 1985; Hofmann and Ambler, 1988].

The light-dependent growth rate is taken from Jassby and Platt [1976]:

$$
\mu_{l}=P_{m}^{B} \tanh \left[\alpha I(z, t) / P_{m}^{B}\right] .
$$

The maximum chlorophyll-specific carbon uptake rate $\left(P_{m}^{B}\right)$ for a cyclonic upwelling event of April 1979 was measured by Yoder et al. [1983]; values ranged from 15 to $19 \mathrm{mg} \mathrm{C} \mathrm{mg}$ chlorophyll (chl) $a^{-1} \mathrm{~h}^{-1}$. Hofmann and Ambler [1988] used a maximum value of $15.8 \mathrm{mg} \mathrm{C} \mathrm{mg} \mathrm{chl} a^{-1} \mathrm{~h}^{-1}$ in a biological model of SAB eddy upwelling, compared with a temperature-dependent [Eppley, 1972] maximum assimilation rate, and concluded that the constant rate reproduced more realistic results. This same value is used and considered constant in the present model over a 12-hour light period. To convert from particulate nitrogen to carbon, a $\mathrm{C} / \mathrm{N}$ weight ratio of 5.68 (the Redfield ratio [Redfield et al., 1963]) is used.

The initial slope of the photosynthesis versus light relationship is $\alpha$, calculated by $\alpha=P_{m}^{B} / I_{k}$, where $I_{k}$ is the half-saturation light intensity. The value used for $I_{k}$ is $1.98 \mathrm{E}$ (einstein) $\mathrm{m}^{-2} \mathrm{~h}^{-1}$ [Yoder et al., 1983, 1985; Hofmann and Ambler, 1988], giving an $\alpha$ of $8.0 \mathrm{mg} \mathrm{C} \mathrm{mg} \mathrm{chl} a^{-1} \mathrm{E}^{-1} \mathrm{~m}^{2}$ 

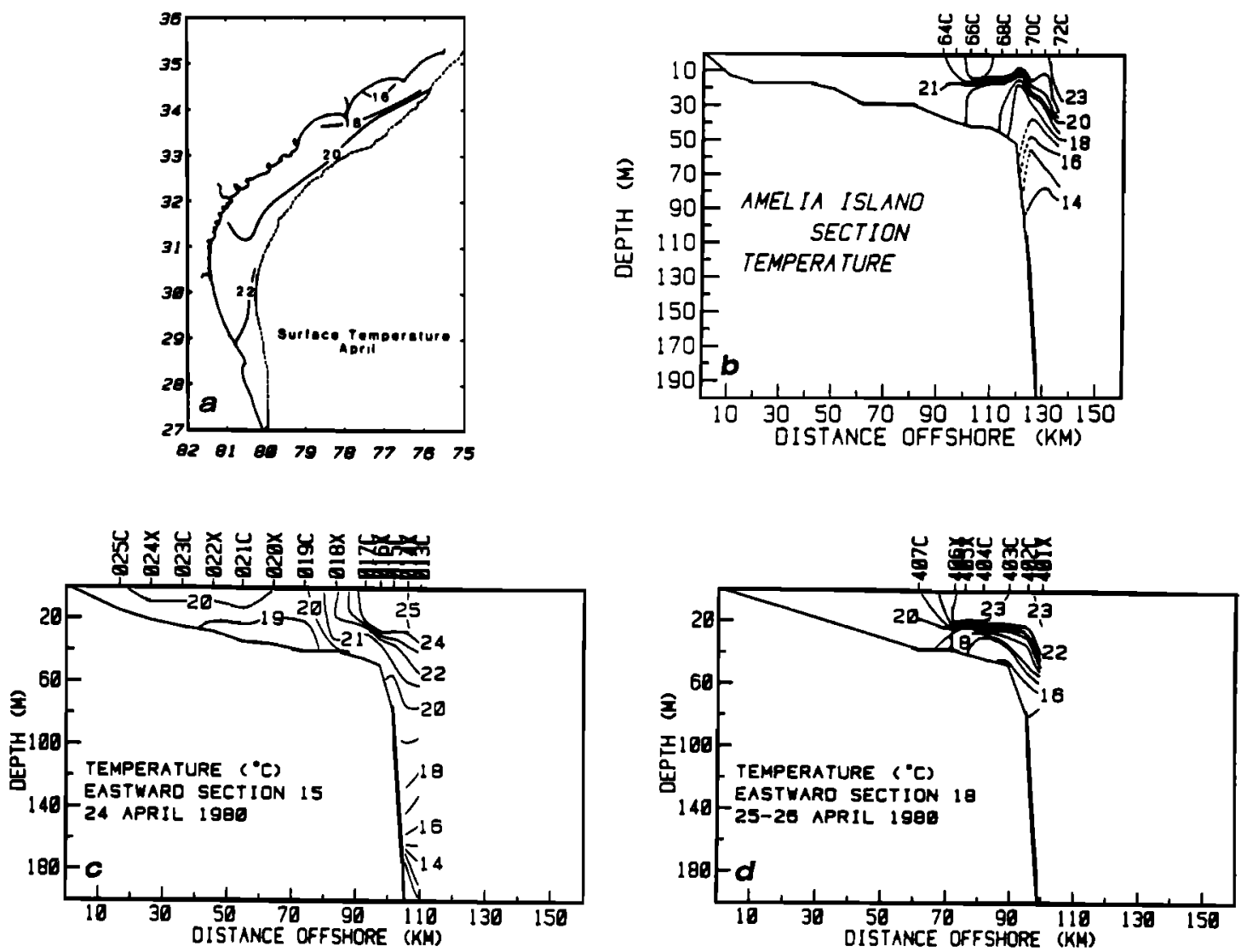

Figure 6. Measured temperatures (degrees Celsius) over the SAB. (a) Average surface temperature for April (from Atkinson et al. [1983]); (b) temperature profile for April 21, 1979, at $30.5^{\circ} \mathrm{N}$ (from Yoder et al. [1981]); (c) temperature profile for April 24, 1980, at 30 $\mathrm{N}$ (from Atkinson [1985]); (d) temperature profile for same latitude as Figure 6c for April 24-25 (from Atkinson [1985]).

[Yoder et al., 1985]. In comparison, North Sea picoplankton had an average $\alpha$ of $55.56 \mathrm{mg} \mathrm{C} \mathrm{mg} \mathrm{chl} a^{-1} \mathrm{E}^{-1} \mathrm{~m}^{-2}$, with associated maximum chlorophyll-specific carbon uptake rate $\left(\mu_{m}\right)$ of $6.01 \mathrm{mg} \mathrm{C} \mathrm{mg} \mathrm{chl} a^{-1} \mathrm{~h}^{-1}$ [Howard and Joint, 1989]. This yields an $I_{k}$ approximately 1 order of magnitude less than that measured for the phytoplankton assemblage in SAB cyclonic eddy events.

The light field as a function of depth and time is given by

$$
I(z, t)=\delta I_{0} \sin [\pi(t-a) / d] e^{-k z} .
$$

Platt et al. [1990] determined that the light field is best represented by the sine function. Values of $I_{0}$ have been measured for April in the SAB; they range between 2.2 and $4.4 \mathrm{E} \mathrm{m}^{-2} \mathrm{~h}^{-1}$ [Hofmann and Ambler, 1988]. A value of 4.0 $\mathrm{E} \mathrm{m}^{-2} \mathrm{~h}^{-1}$ is used here, as by Hofmann and Ambler [1988], and is multiplied by $\delta=0.5$ to compensate for the use of a constant attenuation coefficient throughout the duration of the model. The time of sunrise is given as $a$, taken in this model to be $0600 \mathrm{LT}$, and $t$ is the time of day. The photoperiod length $d$ is taken to be a constant 12 hours, and $I(z, t)$ is set to zero for the next 12 hours to simulate darkness. An average attenuation coefficient $k$ was also determined for eddy upwellings to be $0.10 \mathrm{~m}^{-1}$ [Yoder et al., 1983; Hofmann and Ambler, 1988), and $z$ is the depth in meters.

With a background dissolved organic carbon attenuation of $\sim 0.05 \mathrm{~m}^{-1}$ in the Gulf Stream [Walsh et al., 1992] and a water attenuation of $\sim 0.03 \mathrm{~m}^{-1}$, such an average total attenuation of $0.10 \mathrm{~m}^{-1}$ corresponds to a mean chlorophyll concentration of $0.67 \mu \mathrm{g} \mathrm{L}^{-1}$, assuming a chlorophyllspecific absorption coefficient of $0.03 \mu \mathrm{g}^{-1} \mathrm{~L} \mathrm{~m}^{-1}$. The $1 \%$ light level from this total attenuation coefficient is then 46.05 $\mathrm{m}$, so that the euphotic zone integrated chlorophyll equivalent to this chlorophyll concentration becomes $30.7 \mathrm{mg} \mathrm{m}^{-2}$. Use of this constant $k$ would tend to underestimate the light-limited growth rate for chlorophyll concentrations of less than $0.67 \mu \mathrm{g} \mathrm{L}^{-1}$ and overestimate the light-limited growth rate for concentrations greater than this value. However, as the integrated euphotic zone chlorophyll concentration for the model period is below $30 \mathrm{mg} \mathrm{m}^{-2}$ for the first 5 days and above this for the last 5 days, the use of a constant attenuation coefficient instead of a chlorophyll-dependent attenuation coefficient [Walsh et al., 1988, 1989] contributes to the simplicity of this model. This is similar to the model of Franks et al. [1986], in which the use of the constant attenuation coefficient $\left(0.08 \mathrm{~m}^{-1}\right)$ had little effect on the model results.

The nutrient-dependent growth rate is calculated from

$$
\mu_{n}=v_{m} N /\left(k_{s}+N\right),
$$

the Michaelis-Menten formulation of nutrient uptake, where $N$ is the nitrate concentration. The maximum nitrogen- and carbon-specific uptake rate $v_{m}$ is given by the product of $P_{m}^{B}$, the maximum chlorophyll-specific carbon uptake rate, 
and the chlorophyll to carbon ratio (by weight) $v_{m}=\boldsymbol{P}_{m}^{B}$ (chl/C). The chlorophyll to carbon ratio of the phytoplankton assemblage found in an eddy upwelling is $0.025 \mathrm{mg} \mathrm{chl} \mathrm{mg}$ $\mathrm{C}^{-1}$ [Hofmann and Ambler, 1988], giving a $v_{m}$ of $0.395 \mathrm{~h}^{-1}$ or $4.74 \mathrm{~d}^{-1}$ for a 12-hour day compared to $2.0 \mathrm{~d}^{-1}$ used by the Franks et al. [1986] study and $1.0 \mathrm{~d}^{-1}$ used by Marra and Ho [1993]. A biological model of the Gulf of Mexico [Walsh et al., 1989] had a $v_{m}$ of $0.12 \mathrm{~h}^{-1}$ over a 24-hour day, or 0.24 $h^{-1}$ over a 12 -hour day, at $25^{\circ} \mathrm{C}$. This rate is $61 \%$ of the value used in our model, with the lower rate resulting from lower intrinsic growth rates of oceanic picoplankton.

The biological model initializes the nutrient and chlorophyll fields at $0600 \mathrm{LT}$ on day 1 , so that each day of the model begins and ends at sunrise. Initial nitrate concentrations are set by the temperature relationship given by (6) except for the euphotic zone nitrate levels, which are set to $0.1 \mu M \mathrm{~N}$, a value consistent with measured values in the absence of an eddy [Yoder et al., 1983]. Likewise, initial euphotic zone chlorophyll concentrations are set at $0.1 \mu \mathrm{g}$ chl $\mathrm{L}^{-1}$ comparable to Gulf Stream levels [Yoder et al., 1981], and to zero within the aphotic zone; these values are chosen as conservative initialization data so as to exert minimal influence on the model results.

Most of the biological parameters are set by measurements taken from eddy upwelling regions [Yoder et al., 1981, 1983; Hofmann and Ambler, 1988]. The half-saturation constant $k_{s}$ for nitrate uptake was taken to be $0.0 \mu M$ by Hofmann and Ambler [1988]; this value is replaced in our model by a more realistic $k_{s}$ of $1.5 \mu M$ [Walsh, 1988], similar to the value measured for summer intrusions within the SAB [Hofmann and Ambler, 1988] and more representative of balanced growth. It is likely that similar phytoplankton assemblages represent the colonizing populations of both the cyclonic eddies and the summer intrusions [Yoder, 1985], and thus the phytoplankton assemblages should have similar physiological properties. This value is compared to values of 0.1 and $0.2 \mu M$ used for oceanic phytoplankton in the studies of Franks et al. [1986] and Marra and Ho [1993], respectively.

The fourth term of (8) represents the phytoplankton loss due to sinking. The sinking rate $w_{s}$ (in meters per day) is given by the expression

$$
w_{s}=\lambda[\mathrm{chl}]^{2},
$$

so that the sinking rate is a function of the square of the chlorophyll concentration, in micrograms chlorophyll per liter. The parameter relating the concentration to the sinking velocity $\lambda$ has units of $\mathrm{L}^{2}(\mu \mathrm{g} \mathrm{chl})^{-2} \mathrm{~m} \mathrm{~d}^{-1}$, so that when $\lambda=1$, the sinking rate for a chlorophyll concentration of 10

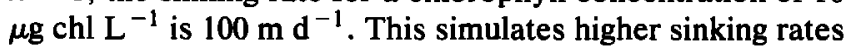
at chlorophyll concentrations at which aggregation may occur [Alldredge and Gotschalk, 1989; Riebesell, 1991]. Yoder [1985] described the phytoplankton assemblage of an eddy as being dominated by diatoms, some of which form aggregates of $\sim 1-\mathrm{mm}$ diameter. The effects of various values of $\lambda$ on the results of the model will be shown later.

In the absence of horizontal advection within a strictly one-dimensional model, any nonuniform vertical movement of water will result in a mass buildup within a grid box. Even if vertical advection is uniform throughout the interior of the water column, the top and bottom boxes will be either emptied or overfilled with mass unless there is no vertical velocity. In the real world, these possibilities are eventually prevented by horizontal exchange. The last terms of (7) and (8), $-H N$ and $-H P$, respectively, represent horizontal advective-loss terms. The true form of the horizontal advective term,

$$
\partial[N, P] / \partial t=-\partial u[N, P] / \partial x-\partial v[N, P] / \partial y,
$$

cannot be determined in a one-dimensional numerical model, as $[N, P]_{[i, j] \pm 1}$ are not known. The values for $(u, v)$ from the physical model are known, however, and can be used to calculate this term. Expanding the terms in (13) gives

$$
\begin{aligned}
\partial[N, P] / \partial t=-u \partial[N, P] / \partial x-[N, P] \partial u / \partial x \\
-v \partial[N, P] / \partial y-[N, P] \partial v / \partial y .
\end{aligned}
$$

The second and fourth terms, $-[N, P](\partial u / \partial x+\partial v / \partial y)$, can be calculated from the vertical nitrate and chlorophyll fields and the continuity equation,

$$
\partial w / \partial z=-(\partial u / \partial x+\partial v / \partial y)
$$

The first and third terms of (14) can be estimated from chlorophyll and nitrate gradients across an eddy, where $N_{i}$ and $\boldsymbol{P}_{i}$ represent the nitrate and chlorophyll values inside the modeled vertical box, and $N_{o}$ and $P_{o}$ represent different values of the variables outside the eddy in the different cases examined. The advective loss term $H$ can then be written as

$$
\begin{gathered}
H(N, P)=-[N, P] \partial w / \partial z+u\left[N_{i}-N_{o}, P_{i}-P_{o}\right] / \Delta x \\
+v\left[N_{i}-N_{o}, P_{i}-P_{o}\right] / \Delta y .
\end{gathered}
$$

In a quasi-one-dimensional model, however, only those horizontal fluxes out of the vertical box can be accounted for. This leads to certain modifications of (14) depending upon the direction of the horizontal fluxes. Ascertaining horizontal fluxes into the box requires some knowledge of the external chlorophyll and nitrate fields. The CZCS images processed for this study (1) are not coincident with the complete temporal and spatial range of the model and (2) could be used only to estimate the chlorophyll field within the first optical depth; these images are thus not used to derive boundary conditions. Accordingly, the horizontal fluxes into the box, because of the last two terms of (16), are set to zero at water column depths within the euphotic zone.

However, upon examination of Figure 4, it is seen that the vertical velocities increase between the bottom at the $800-\mathrm{m}$ isobath and the $300-\mathrm{m}$-depth level over this isobath. For a quasi-one-dimensional model, this implies some lateral input of water mass above the $\sim 800$-m-depth level to account for the increased vertical velocities between the two depths. In the biological model this input is provided for by allowing water and its associated nitrate signature to be horizontally transported into the box below the euphotic zone. The nitrate signal of this inflowing water mass is assumed to be equal to the nitrate concentration in the corresponding vertical box of our quasi-one-dimensional model, with the rate of the influx determined by the divergence of the vertical flow field. In practice, this leads to a nitrate source from outside the modeled water column below the 298 -m-depth level and results only in an augmentation of the integrated water column nitrate over the elapsed time of the model, most of which is unused by the simulated phytoplankton, as will be shown later.

The grid box of the biological model is located above the 

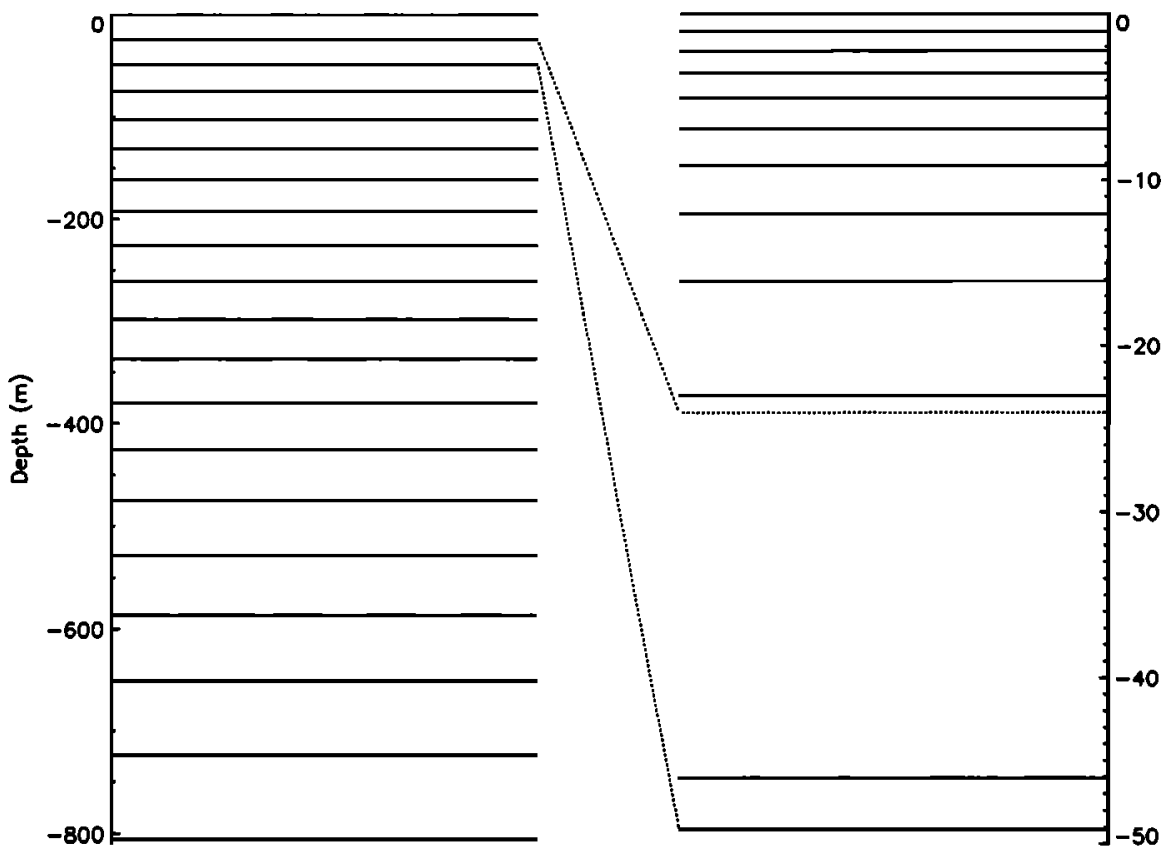

Flgure 7. (left) Vertical grid structure for physical model over $805.5-\mathrm{m}$ isobath; (right) vertical grid structure for euphotic zone of biological model, with dotted lines showing the relative locations of the bottom depths of the first and second model boxes of the physical model.

805.5-m isobath of the physical model, where the upwelling field is strongest (see Figure 4). This is in contrast to observations which suggest that eddy upwellings are centered on the $\sim 200-\mathrm{m}$ isobath [Yoder et al., 1981], though the model's horizontal distance between the 200 - and $800-\mathrm{m}$ isobaths is only $\sim 47 \mathrm{~km}$. At the $800-\mathrm{m}$ isobath of the physical model, there are 19 vertical grid boxes (Figure 7), with an associated 19 temperature (nitrate) values and 20 vertical velocities (the vertical velocities are offset from the temperature values by $\pm 1 / 2$ grid box). The temperature values were used for initializing the nitrate field only below the euphotic zone, which comprised most of the top two boxes of the physical model.

For the purpose of better resolving the euphotic zone, this region is subdivided into 10 grid boxes, the top nine having depths corresponding to $10 \%$ increments of incident PAR. The tenth box has its bottom at the $1 \%$ light depth (see Figure 7), which is $\sim 46 \mathrm{~m}$, using an extinction coefficient of $0.10 \mathrm{~m}^{-1}$. Cubic splines of the velocity and temperature fields of the physical model interpolated values of these fields for the vertical grid of the biological model.

This grid system demands, by the Von Neumann stability condition for the vertical diffusion, a time step of $\sim 9 \mathrm{~min}$. The Courant-Freidricks-Lewy stability condition for advective motion gives a time step requirement of approximately 37 min, so the Von Neumann condition is satisfied with a time step of $6 \mathrm{~min}$. This time step easily satisfies the requirements imposed by the horizontal considerations, where the grid point separation distance of the physical model is $\sim 6 \mathrm{~km}$, horizontal diffusivity is $-2.5 \times 10^{6} \mathrm{~cm}^{2}$ $\mathrm{s}^{-1}$, and horizontal velocities are $\sim 25 \mathrm{~cm} \mathrm{~s}^{-1}$.

\section{Verification Data}

The CZCS images span April 13-21, 1979, and show the color manifestation of several cyclonic eddies. Shipboard data consist of continuous measurements made from April 20 to 22,1979 , over a latitudinal range of $28^{\circ}-\sim 31^{\circ} \mathrm{N}$ (Figure $8 \mathrm{a})$ as well as temperature and biological measurements at $\sim 30.5^{\circ} \mathrm{N}$ over the shelf break from April 22 to 30,1979 (Figures $8 b$ to $8 d$ ). These data are compared to the model.

Satellite. The first image of April 13, 1979 (Plate 1), provides color data from $\sim 26.5^{\circ}$ to $\sim 31^{\circ} \mathrm{N}$. Within this region there was one large pigment patch adjacent to the Gulf Stream and separated for most of its length from the coastal stocks by relatively low chlorophyll $\left(0.2-0.5 \mu \mathrm{g} \mathrm{L}^{-1}\right)$ water. In this analysis we assume that the CZCS color data for the center of the upwelled water are not contaminated by phaeopigments and/or colored dissolved organic carbon [Walsh et al., 1992]. This eddy event will be referred to as eddy 1 . The high-chlorophyll patch was centered at $\sim 29.5^{\circ} \mathrm{N}$ and was $\sim 150 \mathrm{~km}$ long (north-south) and $\sim 11 \mathrm{~km}$ wide (east-west).

As in other descriptions of such cyclonic eddies [Yoder et al., 1981; Pietrafesa et al., 1985; Lee et al., 1985], there were filaments of low-chlorophyll Gulf Stream water on the shoreward side of the eddy. The southern portions of eddy 1 were obscured by clouds, but the eddy may have been continuous with the coastal chlorophyll field at $\sim 28.5^{\circ} \mathrm{N}$. The northern tip of the eddy was at $30.3^{\circ} \mathrm{N}$. Apparent chlorophyll values within eddy 1 on April 13 ranged from $<0.5$ to $>2.0 \mu \mathrm{g} \mathrm{L}^{-1}$,

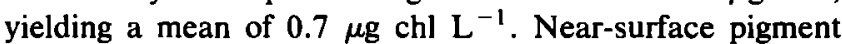
values in the northern part of this eddy, where the Gulf Stream looped around, were $\sim 0.5 \mu \mathrm{g} \mathrm{L}^{-1}$; this region is considered to coincide with the modeled grid box of strongest upwelling.

Eddy 1 was next seen on April 17, 1979 (Plate 2). Assuming a northward movement of $\sim 35 \mathrm{~km} \mathrm{~d}^{-1}$ for such an eddy [Yoder et al., 1983], the center of eddy 1 should have been at $-31^{\circ} \mathrm{N}$ by this date. The eddy was, in fact, centered at $\sim 31.5^{\circ} \mathrm{N}$, with $\sim 100-\mathrm{km}$ length and $\sim 35-\mathrm{km}$ width, about 

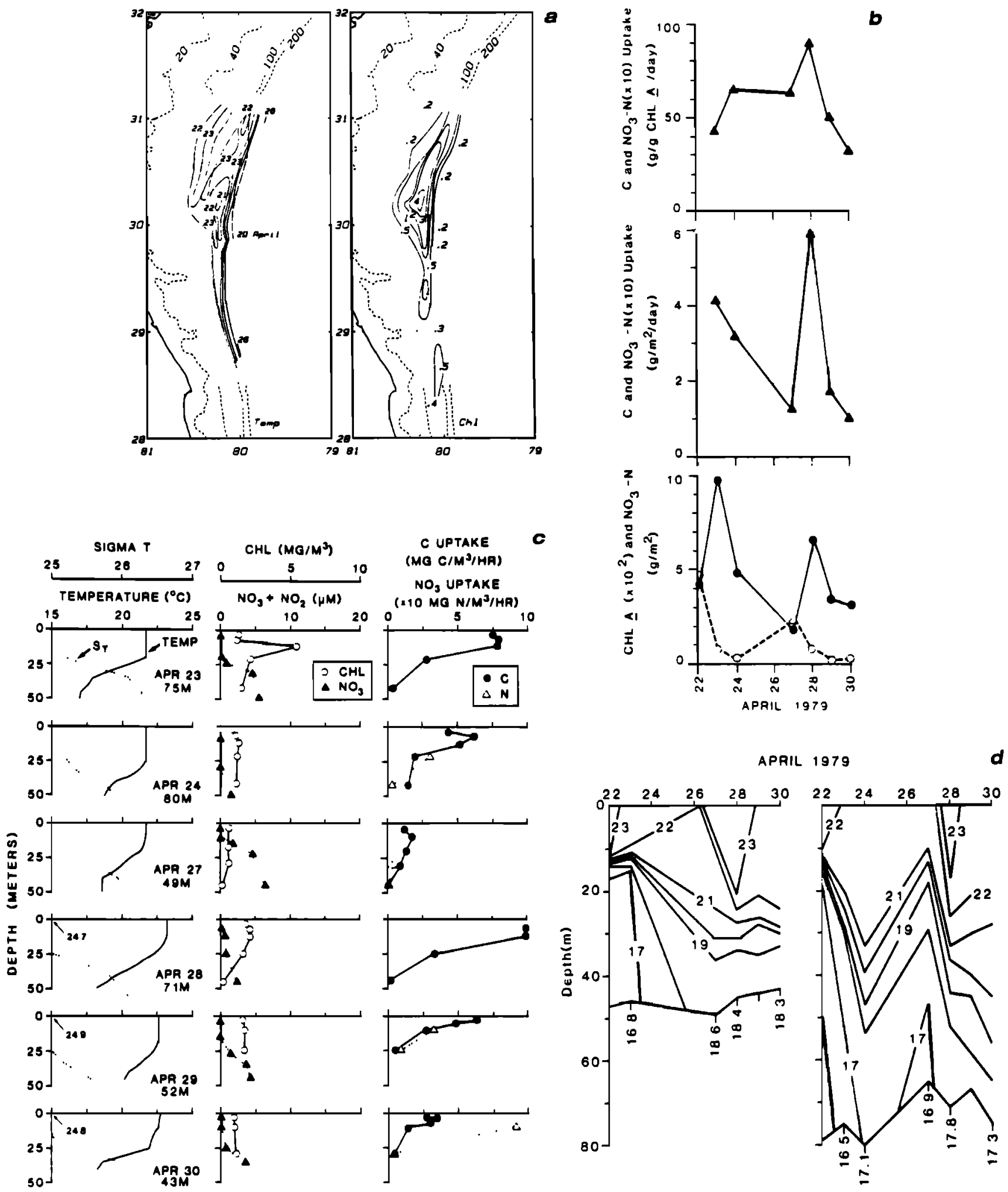

Figure 8. (a) Surface measurements of temperature (degrees Celsius) and chlorophyll (micrograms per liter) taken from a ship on April 20-22, 1979, in the southern SAB, with the location of the thermal front on April 20 marked by a dotted line (from Yoder et al. [1981]); (b) measurements made at $\sim 30.5^{\circ} \mathrm{N}$ in April 1979 over the shelf break; (c) profiles of biological and physical quantities over the same time period at the isobaths noted; (d) temperature measurements at the same locations over the same time period. (Figures $8 \mathrm{~b}, 8 \mathrm{c}$, and $8 \mathrm{~d}$ reprinted from Continental Shelf Research, volume 1, J. A. Yoder, L. P. Atkinson, S. S. Bishop, E. E. Hofmann, and T. N. Lee. Effect of upwelling on phytoplankton productivity of the outer southeastern United States continental shelf, pp. 385-404, copyright 1983, with kind permission from Pergamon Press Ltd., Headington Hill Hall, Oxford 0X3 OBW, UK.) 


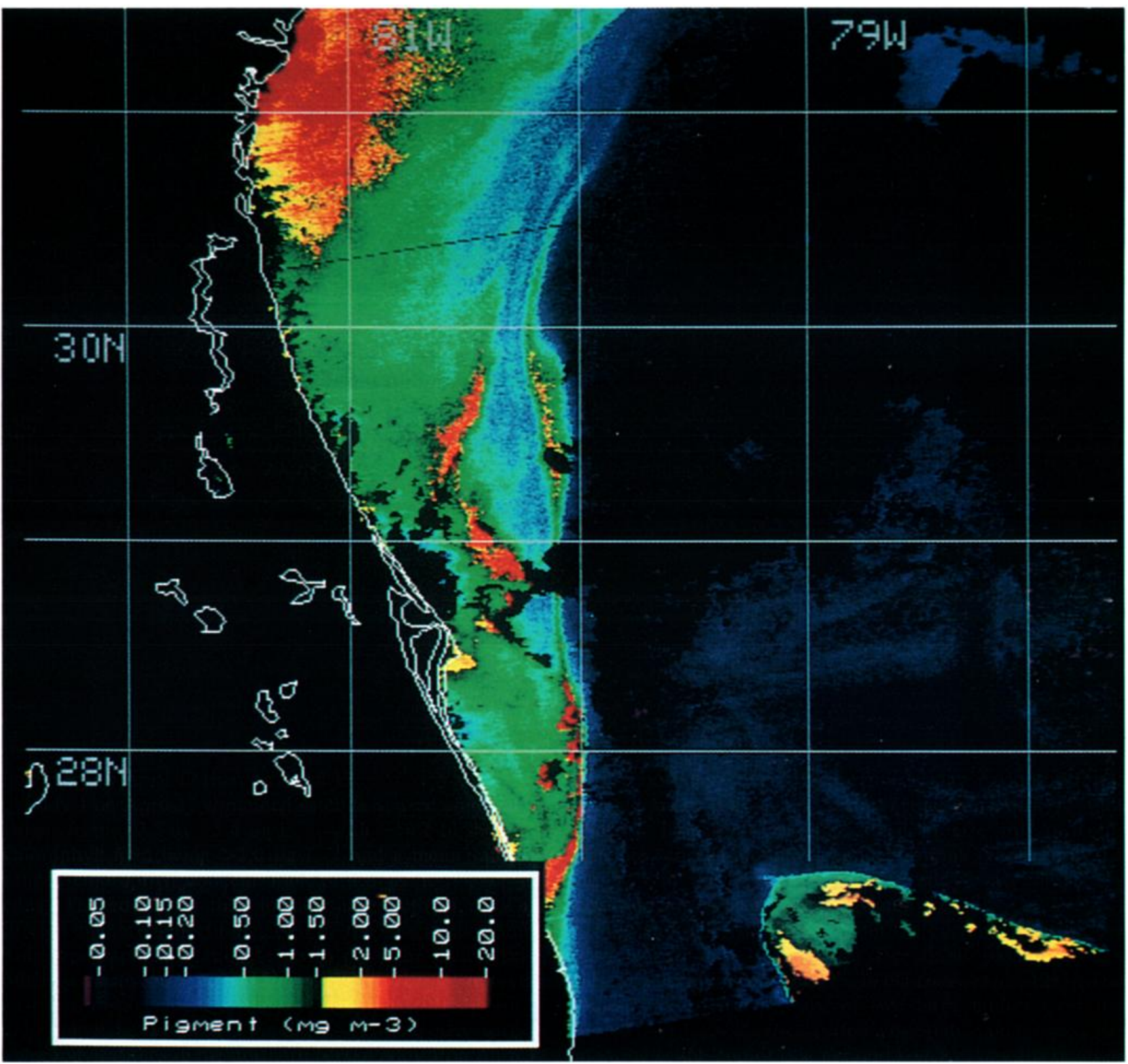

Plate 1. CZCS image for April 13, 1979, depicting eddy 1 over the shelf break off Florida. The main body of the eddy is between $29^{\circ}$ and $30^{\circ} \mathrm{N}$, just west of the $80^{\circ} \mathrm{W}$ parallel.

twice the area of eddy 1 when it was at $29.5^{\circ} \mathrm{N} 4$ days earlier. Some remnants of the low-chlorophyll Gulf Stream filaments were still evident on the shoreward side and the southern end of the eddy. The eddy was much more ellipsoidal, however, on April 17 than on April 13.

Eddy 1 on April 17 contained satellite-sensed chlorophyll values from $\sim 0.5$ to $>5.4 \mu \mathrm{g} \mathrm{L}^{-1}$, with $\sim 50 \%$ of the eddy chlorophyll field being $>2.0 \mu \mathrm{g} \mathrm{L}^{-1}$ and a mean satellitesensed chlorophyll concentration of $1.8 \mu \mathrm{g} \mathrm{L}^{-1}$ over the eddy. The eddy was then located just south of the Gulf Stream offshore deflection caused by the Charleston Bump. This topographical feature tends to push the Gulf Stream offshore north of $\sim 32^{\circ} \mathrm{N}$ [Singer et al., 1983]: note the eastward displacement of the $0.75-1.50 \mu \mathrm{g} \mathrm{L}^{-1}$ isopleth of chlorophyll between $32.0^{\circ}$ and $32.5^{\circ} \mathrm{N}$. The near-surface chlorophyll values in the northern part of eddy 1 on April 17 were $\sim 0.75-1.50 \mu \mathrm{g} \mathrm{L}^{-1}$ and will be compared to the model results later.

The April 17 image (Plate 2) also shows another eddy (eddy 2), at approximately $33^{\circ} \mathrm{N}$, which had moved $\sim 50 \mathrm{~km}$ to the northeast over the previous 2-day period. Eddy 2 seemed more diffuse on April 17 than on April 15 (not shown), though it was unchanged in size by April 17. Satellite-sensed chlorophyll concentrations average only 0.5 $\mu \mathrm{g} \mathrm{L}^{-1}$ in this second eddy; the eddy was completely enclosed by lower-chlorophyll water.

Ship and moored array. From the current meter on the $75-\mathrm{m}$ isobath at $\sim 31.5^{\circ} \mathrm{N}$, eddy 1 probably passed through this area beginning on April 15, 1979 [Yoder et al., 1983]. The meter showed the passage of two large eddies over the period April 15-27, the second large eddy being past the mooring at the end of this period [Yoder et al., 1983]. 


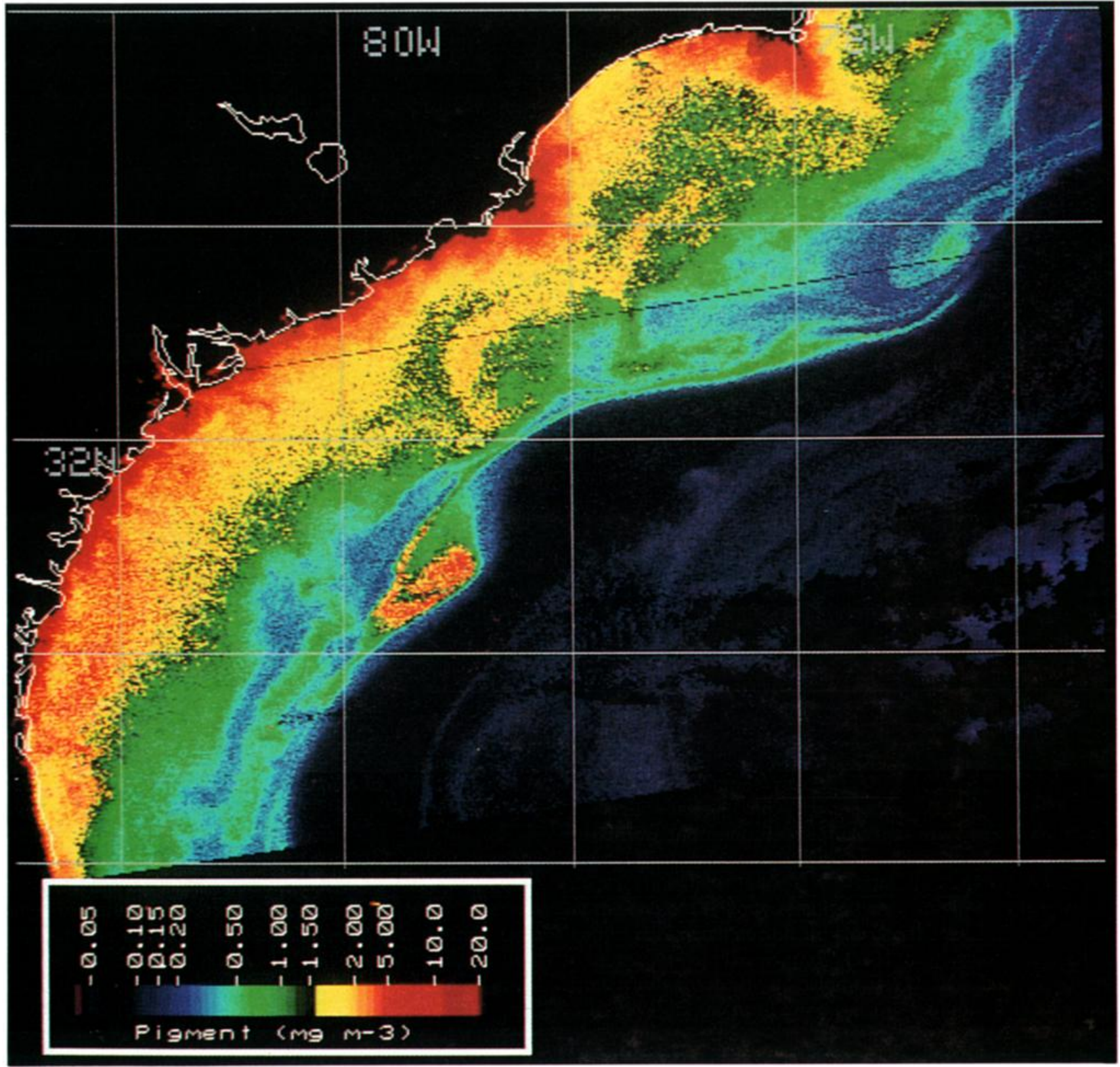

Plate 2. CZCS image for April 17, 1979, depicting eddy 1 over the shelf break off Georgia, between $31^{\circ}$ and $32^{\circ} \mathrm{N}$ and $79^{\circ}$ and $80^{\circ} \mathrm{W}$, and eddy 2 north of the Charleston Bump at $\sim 33^{\circ} \mathrm{N}$ between $77^{\circ}$ and $78^{\circ} \mathrm{W}$.

Yoder et al. [1981] sampled the area from $28^{\circ}$ to $\sim 31^{\circ} \mathrm{N}$ between April 20 and 22 after receiving satellite information suggesting an eddy at $\sim 29^{\circ} \mathrm{N}$ on April 19 (see Figure 8a). This cruise showed the presence of a large eddy within the study area as well as what seems to be a smaller, newer eddy between $28^{\circ}$ and $29^{\circ} \mathrm{N}$ [Yoder et al., 1981]. We will call these eddies 3 and 4 , respectively.

Eddy 3 was sampled during April 20-22, 1979, and the thermal front at the northern end of this eddy was determined by satellite for April 20 [Yoder et al., 1981]. The area in which the northernmost extension of this thermal front was located on April 20 , at $\sim 31^{\circ} \mathrm{N}$, was not sampled until late in the cruise, so that the northern region of the thermal front at the time of the northernmost measurements was approximately 2 days farther north. No biological measurements were taken near this northern region of the thermal front, and so eddy 3 provides few data for comparison with our model. The northernmost measured surface chlorophyll values extend northward out of the sampled area, and only some estimate based on the measured values may be compared with our model results.

Satellite images show these eddies present south of $28^{\circ} \mathrm{N}$ [Atkinson and Menzel, 1985], so that if we assume that the frontal disturbances originate at $\sim 28^{\circ} \mathrm{N}$ and the northward displacement is $\sim 35 \mathrm{~km} \mathrm{~d}^{-1}$ [Yoder et al., 1983], some idea of the age of the eddy results. The $1 \mu \mathrm{g} \mathrm{chl} \mathrm{L}^{-1}$ isopleth of eddy 3 may reach northward close to the area of comparison with the model [Yoder et al., 1983], near where the thermal front wraps around the cold dome at $-31.5^{\circ} \mathrm{N}$, this region being $\sim 10$ days old on April 22, given the location of the thermal front on April 20 (see Figure 8a, surface temperature, dotted line). Model results over this time period will be shown. 
Table 1. Biological Parameters

\begin{tabular}{|c|c|c|c|}
\hline $\begin{array}{l}\text { Measured and Calculated } \\
\text { Parameter }\end{array}$ & Symbol & Measured or Calculated Value & Source \\
\hline $\begin{array}{l}\text { Attenuation coefficient } \\
\text { Initial slope of } P \text { versus } I \\
\text { curve }\end{array}$ & $\begin{array}{l}k \\
\alpha\end{array}$ & $\begin{array}{l}0.1 \mathrm{~m}^{-1} \\
8.0 \mathrm{mg} \mathrm{C}^{-\mathrm{mg}} \mathrm{ml} a^{-1} \text { (Einstein }\end{array}$ & $\begin{array}{l}\text { Yoder et al. }[1983] \\
\text { Hofmann and Ambler [1988] }\end{array}$ \\
\hline Maximum assimilation rate & $P_{m}^{B}$ & $15.8 \mathrm{mg} \mathrm{C} \mathrm{mg} \mathrm{chl} a^{-1} \mathrm{~h}^{-1}$ & Yoder et al. [1983] Hofmann and \\
\hline Maximum incident PAR* & $I_{0}$ & 4.0 Einstein $\mathrm{m}^{-2} \mathrm{~h}^{-1}$ & $\begin{array}{l}\text { Yoder et al. [1983], Hofmann and } \\
\text { Ambler [1988] }\end{array}$ \\
\hline Ratio C/N (by weight) & $\mathrm{C} / \mathrm{N}$ & 5.68 & Redfield et al. [1963] \\
\hline Ratio C/chl (by weight) & $\mathrm{C} / \mathrm{chl}$ & & Hofmann and Ambler [1988] \\
\hline Maximum uptake rate & $V_{m}$ & $0.395 h^{-1}$ & $P_{m}^{B} \times \mathrm{chl} / \mathrm{C}$ \\
\hline External chlorophyll field & {$[\mathrm{chl}]_{0}$} & $0.1 \mu \mathrm{g} \mathrm{L}^{-1}$ in euphotic zone & $\begin{array}{l}\text { Bishop et al. [1980], Yoder et al. } \\
\text { [1981] }\end{array}$ \\
\hline External nitrate field & {$\left[\mathrm{NO}_{3}\right]_{0}$} & $\begin{array}{l}0.1 \mu M \text { in euphotic zone; model } \\
\text { values below }(\partial N /[\partial x, \partial y])=0\end{array}$ & \\
\hline $\begin{array}{l}\text { Initial model chlorophyll } \\
\text { field }\end{array}$ & {$[\mathrm{chl}]_{i}$} & $\begin{array}{l}0.1 \mu \mathrm{g} \mathrm{chl} \mathrm{L} \\
0 \text { below }\end{array}$ & \\
\hline Initial model nitrate field & {$\left[\mathrm{NO}_{3}\right]_{i}$} & $\begin{array}{l}0.1 \mu M \text { in euphotic zone; model } \\
\text { values below }(\partial N /[\partial x, \partial y])=0\end{array}$ & \\
\hline $\begin{array}{l}\mathrm{NO}_{3} \text { uptake half-saturation } \\
\text { constant }\end{array}$ & $k_{s}$ & $1.5 \mu M \mathrm{NO}_{3}$ & \\
\hline Sinking coefficient & $\lambda$ & $1 \mathrm{~L}^{2} \mathrm{~m} \mu \mathrm{g} \mathrm{chl}^{-2} \mathrm{~d}^{-1}$ & \\
\hline
\end{tabular}

*PAR, photosynthetically active radiation.

The chlorophyll manifestation of eddy 4 can be seen in its early phases off Cape Canaveral, Florida, from the April 20-22, 1979, cruise (see Figure 8a, chlorophyll measurements). Eddy 4 seems to have its northernmost extent at $\sim 29^{\circ} \mathrm{N}$ on April 20 , so that it may be $\sim 2-3$ days old when sampled early in the April 20-22, cruise, with a chlorophyll surface manifestation measured from the ship of $\sim 0.3 \mu \mathrm{g}$ $\mathrm{L}^{-1}$ in the northern region [Yoder et al., 1981].

Measurements taken at $30.5^{\circ} \mathrm{N}$ on April 22-30, 1979, were interrupted by a storm on April 25 and 26 [Yoder et al., 1983]. Upon resumption of measurements, an eddy corresponding in estimated age and location to eddy 4 was within the study area. Assuming the aforementioned northward velocity field of $\sim 35 \mathrm{~km} \mathrm{~d}^{-1}$, eddy 4 would be $\sim 7-8$ days old when it reached this latitude on about April 25-26.

The first measurements of eddy event 4 taken at the production stations at $30.5^{\circ} \mathrm{N}$ (see Figure 1 for latitude of stations in relation to model domain) were on April 27, 1979 [Yoder et al., 1983]. These data show inclined isotherms at the $75-\mathrm{m}$ isobath, with the $18^{\circ} \mathrm{C}$ isotherm at $\sim 30 \mathrm{~m}$ and the nitrate profile showing the nutricline beginning at $\sim 15 \mathrm{~m}$ over the 49-m isobath (see Figures $8 \mathrm{c}$ and $8 \mathrm{~d}$ ). The chlorophyll profile shows a relatively uniform distribution throughout the euphotic zone of $\leq 1 \mu \mathrm{g} \mathrm{L}^{-1}$ for April 27 (see Figure $8 c)$. Integrated chl $a$ is $\sim 2 \times 10^{-2} \mathrm{~g} \mathrm{~m}^{-2}$ over the 49 -m water column, and the level of nitrate-nitrogen is approximately 2 orders of magnitude greater, at $\sim 2.1 \mathrm{~g} \mathrm{~m}^{-2}$, with primary production of $\sim 1.1 \mathrm{~g} \mathrm{C} \mathrm{m}^{-2} \mathrm{~d}^{-1}$ (see Figure $8 \mathrm{~b}$ ). These values, though not necessarily obtained at the leading edge of the eddy, are obtained sufficiently close to this leading edge to be used in checking the model output for days 7 and 8.

\section{Results}

Most of the parameters needed as input for the biological model have been measured [Yoder et al., 1981, 1983; Hof- mann and Ambler, 1988]. Other parameters, however, such as the coefficient for the sinking formulation $\lambda$, the parameterization of the horizontal loss terms, and the halfsaturation coefficient for the nutrient uptake formulation, must be chosen so that the values provide the model with realistic rate processes.

The sinking rate parameterization is initially chosen so that a chlorophyll concentration of $1 \mu \mathrm{g} \mathrm{chl} \mathrm{L} \mathrm{L}^{-1}$ results in a sinking velocity of $1 \mathrm{~m} \mathrm{~d}^{-1}$, so that $\lambda=1 \mathrm{~L}^{2} \mu \mathrm{g} \mathrm{chl}^{-2} \mathrm{~m} \mathrm{~d}^{-1}$. The horizontal loss terms depend upon the values of phytoplankton and nitrate concentrations outside the eddy, $\boldsymbol{P}_{o}$ and $N_{o}$. These values are initially set to the same values used to initialize the chlorophyll and nitrate fields of our model, with the external nitrate field below the euphotic zone set equivalent to the internal nitrate concentrations throughout the model duration. The Michaelis-Menten halfsaturation constant, as mentioned previously, is set at 1.5 $\mu M \mathrm{NO}_{3}$, representative of coastal diatoms. All other parameters are as measured and calculated from measured values. The model run using these parameter values is case 1 (Table 1). Other parameter values are changed in subsequent model runs to check the response of the model to parameter variation (Table 2).

\section{Case 1}

Two factors controlling the realized growth of phytoplankton are light and nutrient supply. The hourly light field is invariant from day to day, but the nutrient field changes appreciably as nitrate is upwelled into the euphotic zone. By taking the minimum of the potential growth rates at each space and time point, the realized growth rate, given the chlorophyll field, yields a primary productivity, given in milligrams chl or C per cubic meter per day. This increment of chlorophyll biomass is subject to sinking and horizontal losses.

Starting from an initial chlorophyll field of $0.1 \mu \mathrm{g} \mathrm{chl} \mathrm{L}-1$ throughout the euphotic zone, for example, the first simulated day gives a net chlorophyll maximum of $0.1 \mu \mathrm{g} \mathrm{L}^{-1}$ 
Table 2. Parameter Variation and Resultant Primary Production

\begin{tabular}{|c|c|c|c|}
\hline Case & $\begin{array}{c}\text { Varied } \\
\text { Parameter }\end{array}$ & Value & $\begin{array}{l}\text { Primary } \\
\text { Production, } \\
\mathrm{g} \mathrm{C} \mathrm{m}_{\mathrm{d}^{-1}}^{-2}\end{array}$ \\
\hline 1 & & & 0.8741 \\
\hline 2 & $P_{m}^{B}$ & $7.9 \mathrm{mg} \mathrm{C} \mathrm{mg} \mathrm{chl}^{-1} \mathrm{~h}^{-1}$ & 0.0882 \\
\hline $3 a$ & $\lambda^{m}$ & $2.0 \mathrm{~L}^{2} \mathrm{~m} \mu \mathrm{g} \mathrm{chl}^{-2} \mathrm{~d}^{-1}$ & 0.8297 \\
\hline $3 \mathbf{b}$ & $\ddot{\lambda}$ & $0.5 \mathrm{~L}^{2} \mathrm{~m} \mu \mathrm{g} \mathrm{chl} \mathrm{c}^{-2} \mathrm{~d}^{-1}$ & 0.8898 \\
\hline $4 a$ & {$[\mathrm{chl}]_{0},\left[\mathrm{NO}_{3}\right]_{0}$} & Twice that of case 1 & 0.9986 \\
\hline $4 b$ & {$[\mathrm{chl}]_{0},\left[\mathrm{NO}_{3}\right]_{0}$} & Half that of case 1 & 0.7720 \\
\hline
\end{tabular}

centered around $14 \mathrm{~m}$ at $1718 \mathrm{LT}$ (Figure 9). The $0.1 \mu \mathrm{g} \mathrm{chl}$ $\mathrm{L}^{-1}$ isopleth is between 20 and $30 \mathrm{~m}$ throughout the day, indicating that the upwelling field quickly raises the initial chlorophyll stock toward the surface, causing the subsurface chlorophyll maximum.

By day 3 of the model (not shown), the chlorophyll maximum of $0.5 \mu \mathrm{g} \mathrm{L}^{-1}$ is in the top box of the model, above

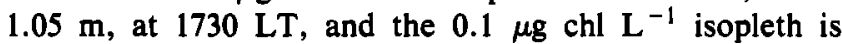
between 23 and $29 \mathrm{~m}$. Day 4 likewise has its chlorophyll maximum in the top model box: $0.9 \mu \mathrm{g} \mathrm{L}-1$ at $1718 \mathrm{LT}$. The $0.1 \mu \mathrm{g} \mathrm{chl} \mathrm{L}{ }^{-1}$ isopleth is between 27 and $31 \mathrm{~m}$ for day 4 . From day 5 onward, the chlorophyll maximum occurs progressively deeper and earlier; it is at $10.6 \mathrm{~m}$ by day 10 at 1618 LT (Figure 10). The $0.1 \mu \mathrm{g} \mathrm{chl} \mathrm{L}^{-1}$ isopleth becomes deeper as well, reaching below $45 \mathrm{~m}$ by day 10 .

The chlorophyll field is not solely a function of the primary production field, of course. The upwelling both provides nitrate to the euphotic zone and results in a horizontal divergence of flow. This divergence, together with the horizontal gradient in chlorophyll and nitrate, leads to a loss of both chlorophyll and nitrate in the quasi- $x$ and $-y$ directions. The horizontal loss for both chlorophyll and nitrate (per 6-min time step) is $\sim 10^{-3}$ of the chlorophyll and nitrate concentrations present.

The euphotic zone integrated chlorophyll and nitrate values for the full 10 days of the model are shown in Figure 11. It is easily seen that the chlorophyll field has no discernible diurnal effect on the nitrate field until after 2 full days, and integrated nitrate values continue to increase throughout the model period. The euphotic zone integrated primary productivity is shown in Figure 12 for the 10-day period. This will be compared to measurements later.

The potential and realized growth rates as fractions of the maximum possible growth rate for the full 10-day period are shown in Figures 13, 14, 15, and 16. The maximum realized growth rate is 0.4 times the maximum possible growth rate and occurs on day 6 at a depth of $\sim 6 \mathrm{~m}$ at $0954 \mathrm{LT}$. The average realized growth rate over the 1024 -hour periods, however, is only 0.03 times the maximum growth rate $(0.07$ $\boldsymbol{P}_{m}^{B}$ for the daylight periods only); nutrient limitation results in an average euphotic zone potential growth rate of $0.7 P_{m}^{B}$, while light limitation gives an average euphotic zone potential growth rate of only $0.05 P_{m}^{B}\left(0.10 P_{m}^{B}\right.$ for the light periods). Of special note is the fact that the light-limited potential growth rate never reaches 0.8 times the maximum growth rate. The growth-irradiance characteristics of this phytoplankton assemblage show it to be capable of utilizing light levels higher than those which occur in the model. It should be recalled, however, that the light field is dependent on the constant value of the attenuation coefficient, $0.10 \mathrm{~m}^{-1}$, so that the model light field compared to the real world is underestimated for chlorophyll concentrations of less than $\sim 0.7 \mu \mathrm{g} \mathrm{chl} \mathrm{L}^{-1}$ and overestimated for higher concentrations [Walsh, 1988].

Table 3 shows the 10-day fluxes of chlorophyll and

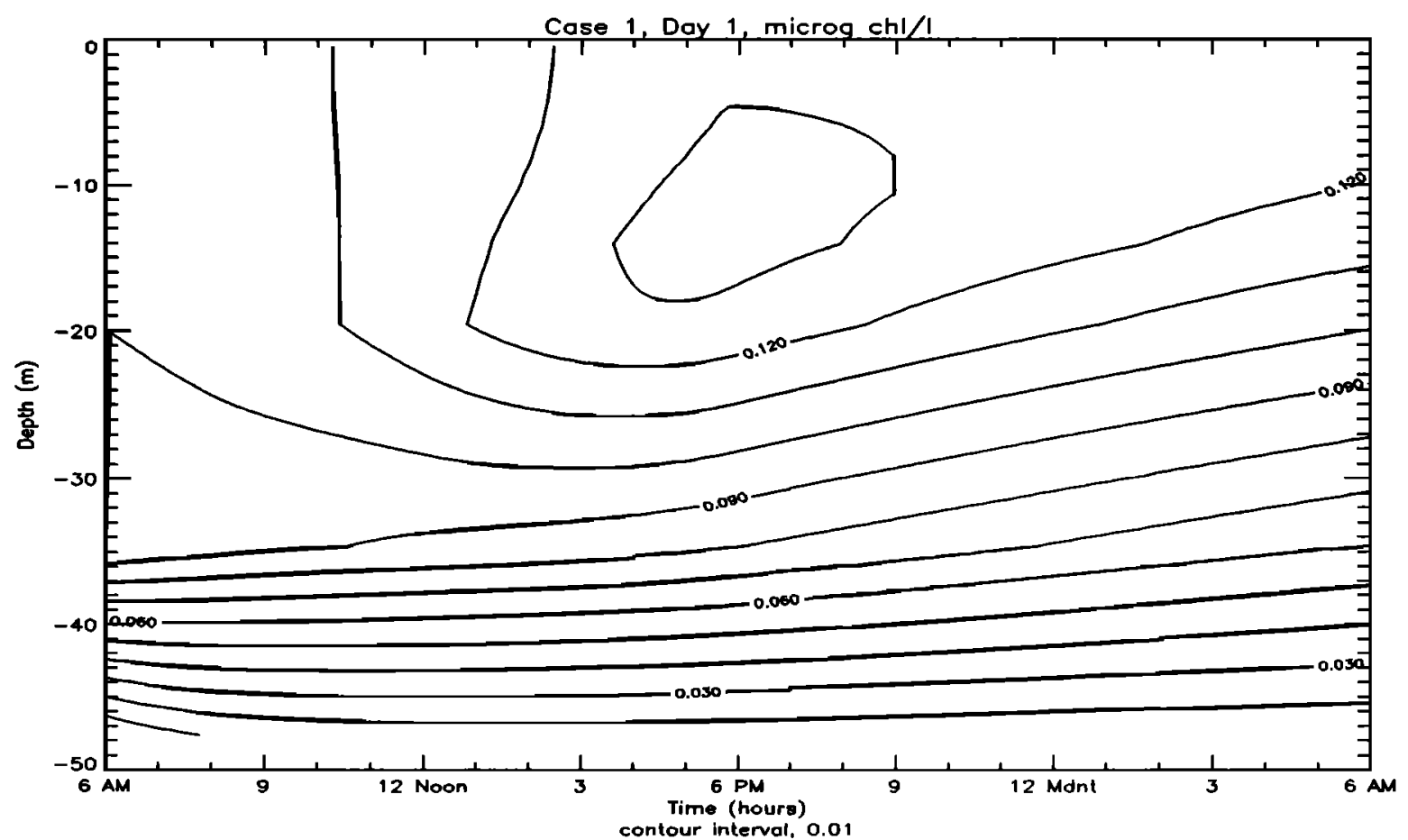

Figure 9. Chlorophyll concentrations (micrograms per liter) over the euphotic zone for day 1 of case 1 . 


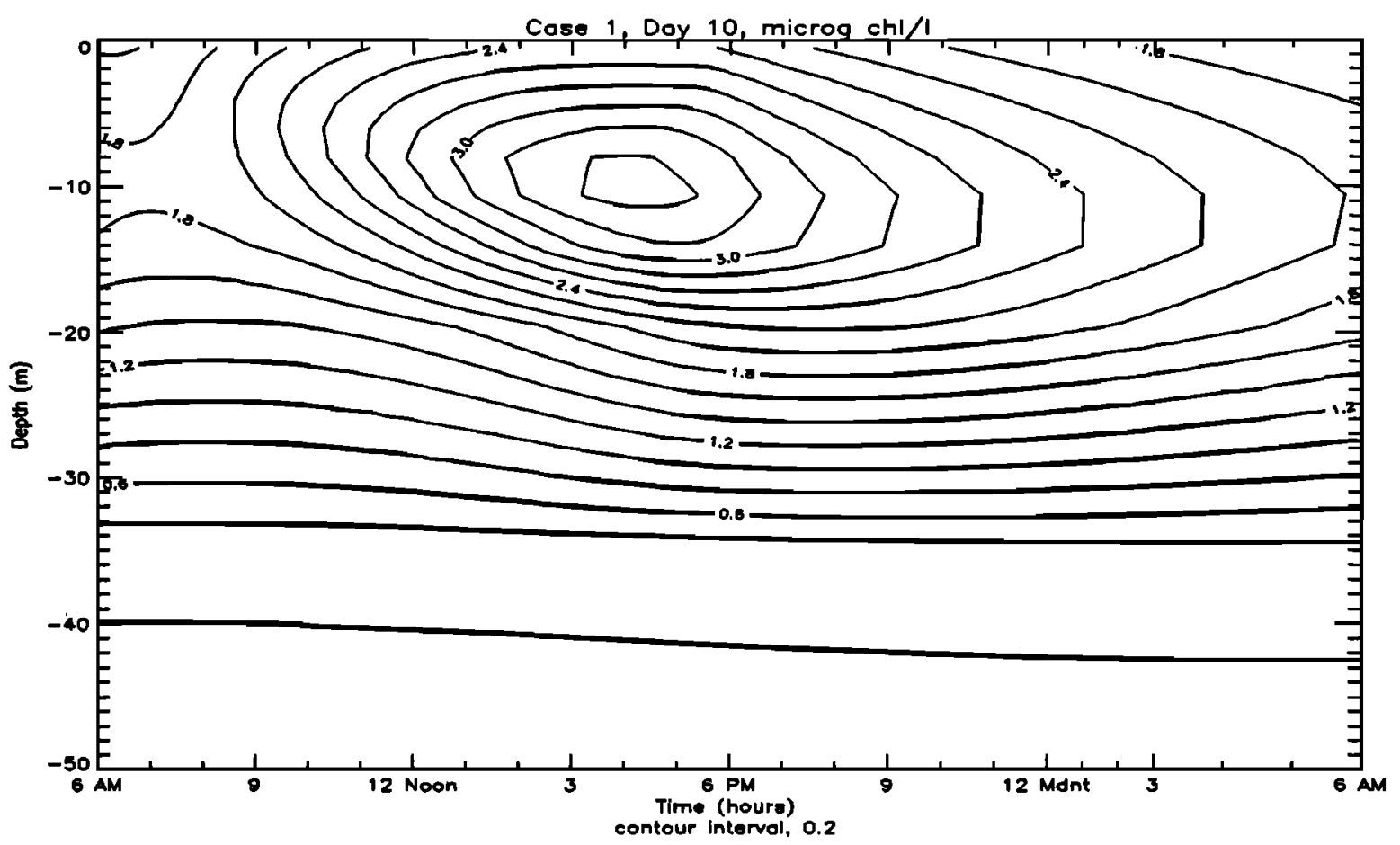

Figure 10. Chlorophyll concentrations (micrograms per liter) over the euphotic zone for day 10 of case 1.

nitrate into and out of the euphotic and aphotic zones in both the horizontal and vertical directions. By using these data to calculate the chlorophyll utilization of upwelled $\mathrm{NO}_{3}$, it is found that only $9.1 \%$ of the $\mathrm{NO}_{3}$ that enters the euphotic zone is converted to particulate nitrogen. Another $75.3 \%$ is lost horizontally, with the remaining
15.6\% left behind in the euphotic zone at the end of the 10-day model run. A total of $1538.9 \mathrm{mg} \mathrm{NO}_{3}-\mathrm{N} \mathrm{m}^{-2}$ is used over the 10-day period, resulting in $8741 \mathrm{mg} \mathrm{C} \mathrm{m}^{-2}$, or $0.9 \mathrm{~g} \mathrm{C} \mathrm{m}^{-2} \mathrm{~d}^{-1}$, fixed by the phytoplankton. Of this, only 1.27 $\mathrm{mg}$ chl ( $50.8 \mathrm{mg} \mathrm{C})$, or $0.6 \%$ of the new production, sinks below the euphotic zone $(\sim 46 \mathrm{~m})$ over the 10 -day period of the model.

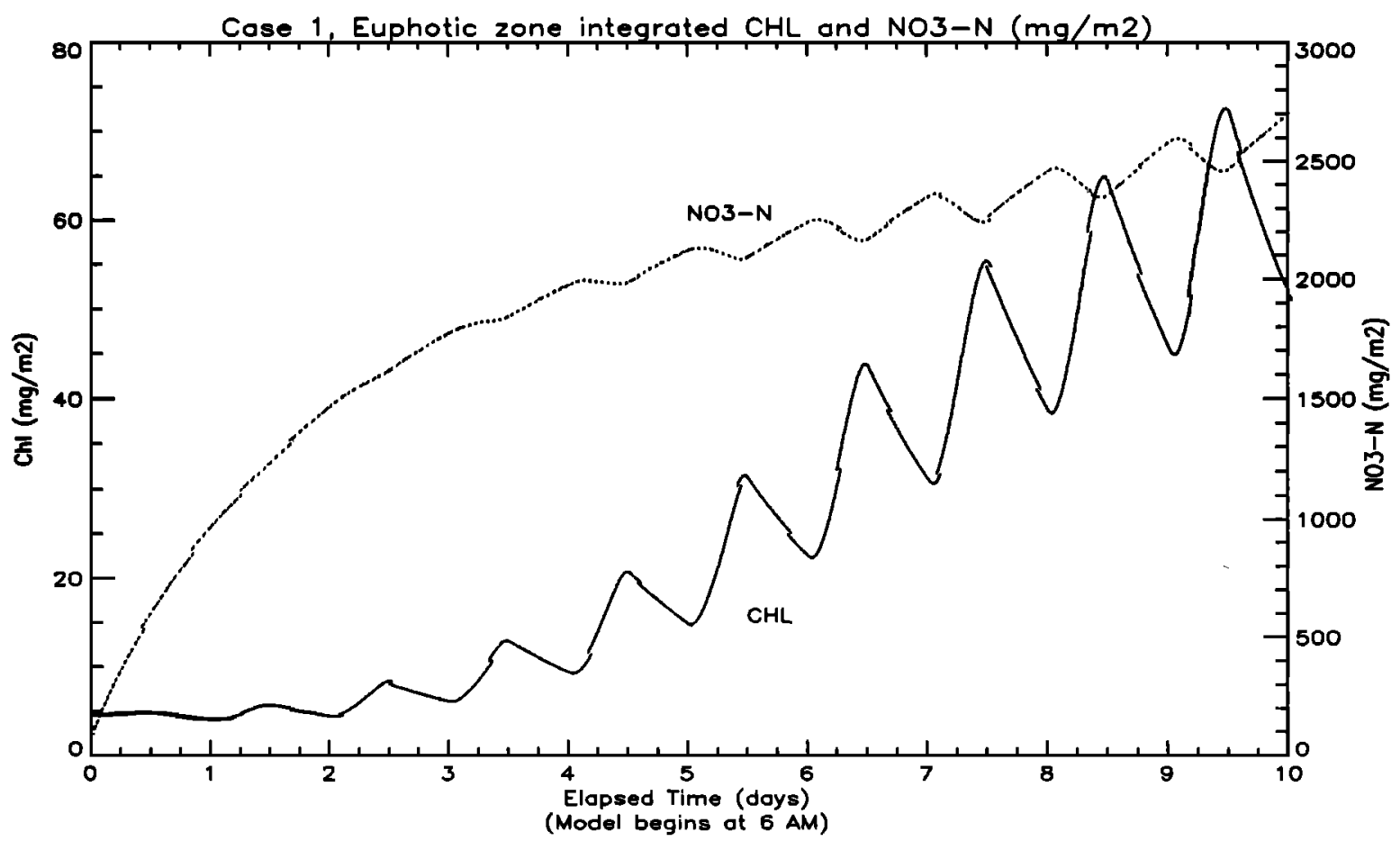

Figure 11. Euphotic zone integrated chlorophyll (milligrams per square meter; solid curve) and integrated nitrate-nitrogen (milligrams per square meter; dotted curve) over 10 days of case 1 , calculated at each time step. 


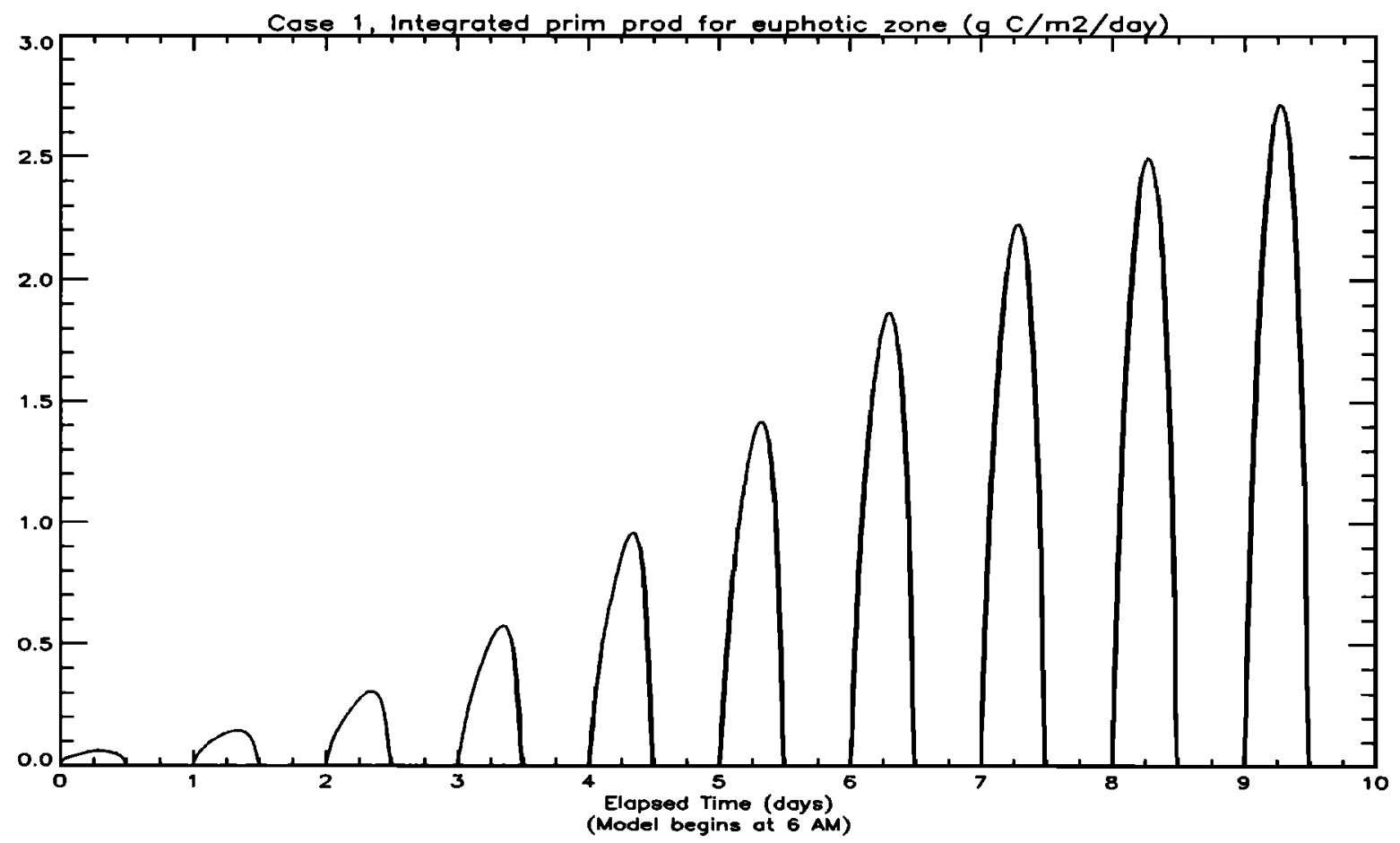

Figure 12. Euphotic zone integrated primary productivity (grams $\mathrm{C}$ per square meter per day) for 10 days of case 1 , calculated at each time step.

\section{Case $2\left(P_{m}^{B}=1 / 2 P_{m}^{B}(\right.$ Case 1))}

By reducing the maximum growth rate to half of that in case 1 , the maximum realized growth rate for case 2 is 0.3 of case $1 P_{m}^{B}$, that is, 0.6 of the case 1 realized maximum. The average realized growth rate drops to 0.02 of the potential maximum rate $\left(P_{m}^{B}\right)$ of case 1 , or 0.60 of the average realized growth rate of case 1 . In comparison, using the potential growth rates from light and nitrate of case 1 , average realized growth rate as a multiplicative function of nutrient and light limitation is 0.02 of case $1 P_{m}^{B}$, or 0.50 of case 1 average realized growth rate. Thus case 2 can serve to provide some idea of the effect of a multiplicative growth rate within the model.

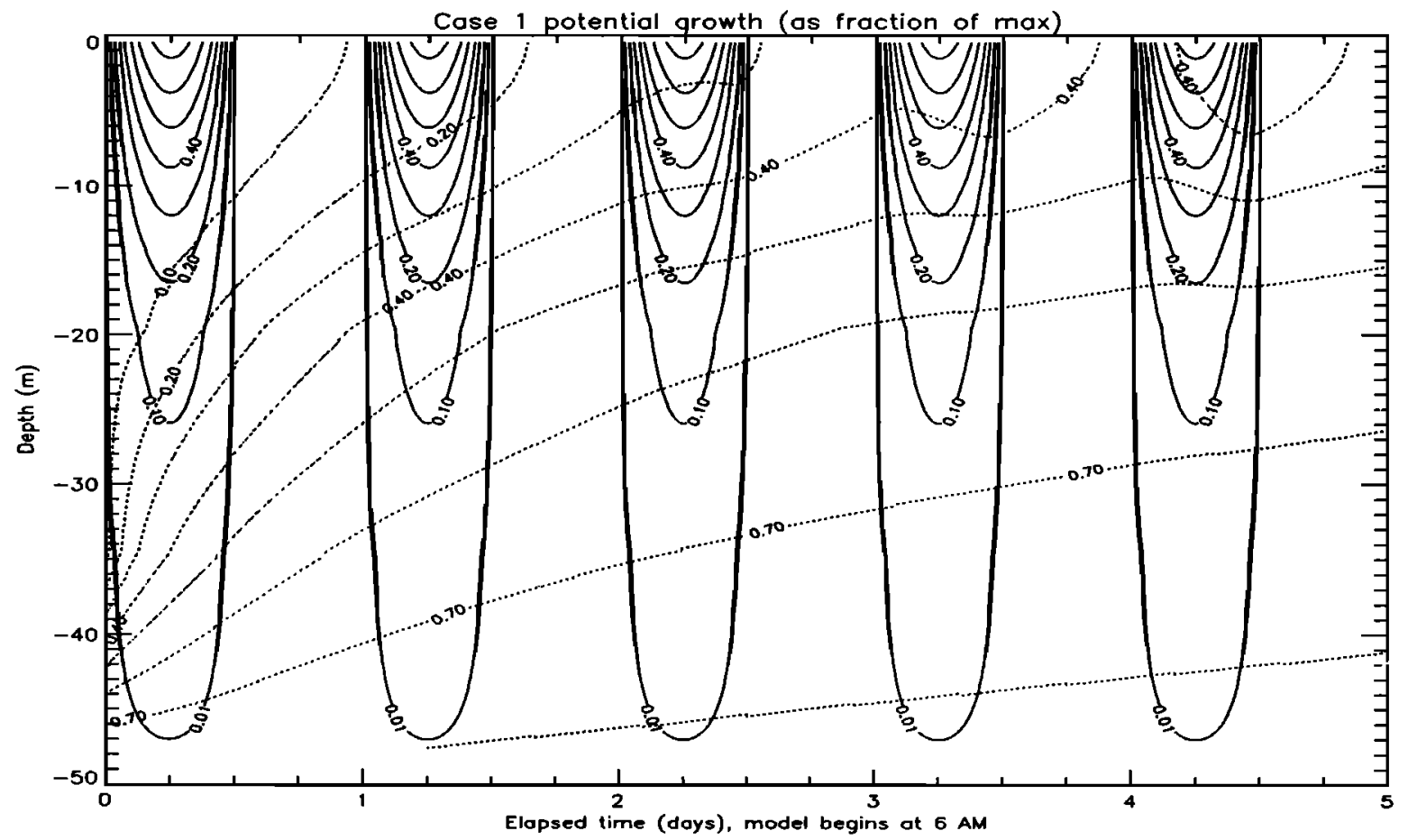

Figure 13. Potential growth as fraction of $P_{m}^{B}$ for days 1-5 of case 1: light limited (solid curve) and nitrate limited (dotted curve). 


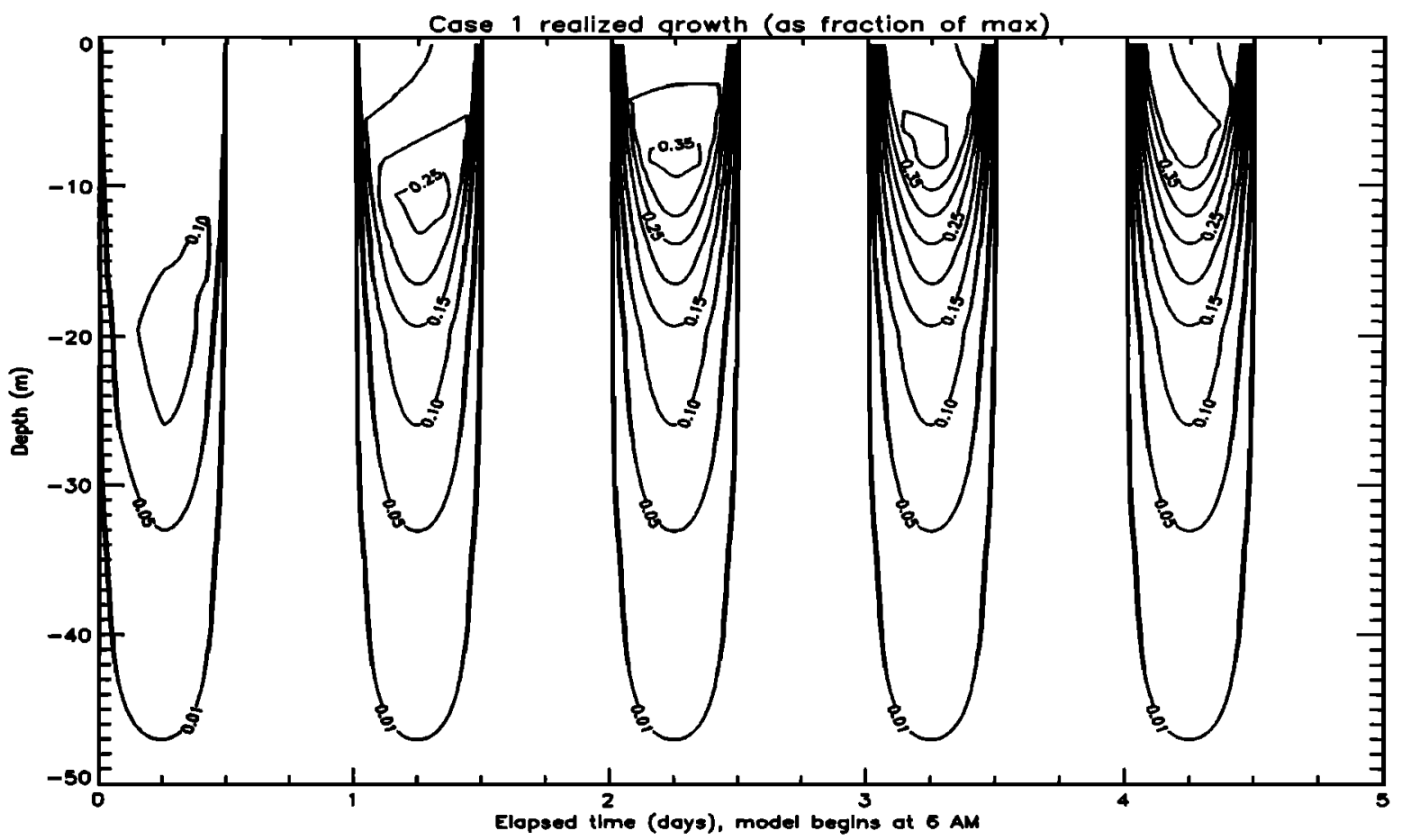

Figure 14. Realized growth as fraction of $P_{m}^{B}$ for days 1-5 of case 1, determined by the minimum at each point of the two potential rates in Figure 13 .

The realized growth rate as a percentage of the case 2 maximum potential growth rate is the same as in case 1 (Figures 14 and 16). However, the impact on the chlorophyll field of the reduced maximum potential growth rate becomes apparent after a few days. Figure 17 shows the chlorophyll field for day 1; compare this to Figure 9. The chlorophyll maximum for day 1 of case 2 is $0.12 \mu \mathrm{g}$ chl $\mathrm{L}^{-1}$, compared to a similar amount of $0.13 \mu \mathrm{g} \mathrm{chl} \mathrm{L}^{-1}$ from case 1 (see Figure 9). By day 2 (not shown), the chlorophyll maximum is at the surface, and it remains there for the duration of the model. The chlorophyll maximum for day 10 of case 2 is instead $0.5 \mu \mathrm{g} \mathrm{chl} \mathrm{L}{ }^{-1}$ (Figure 18), compared with $3.5 \mu \mathrm{g} \mathrm{chl}$

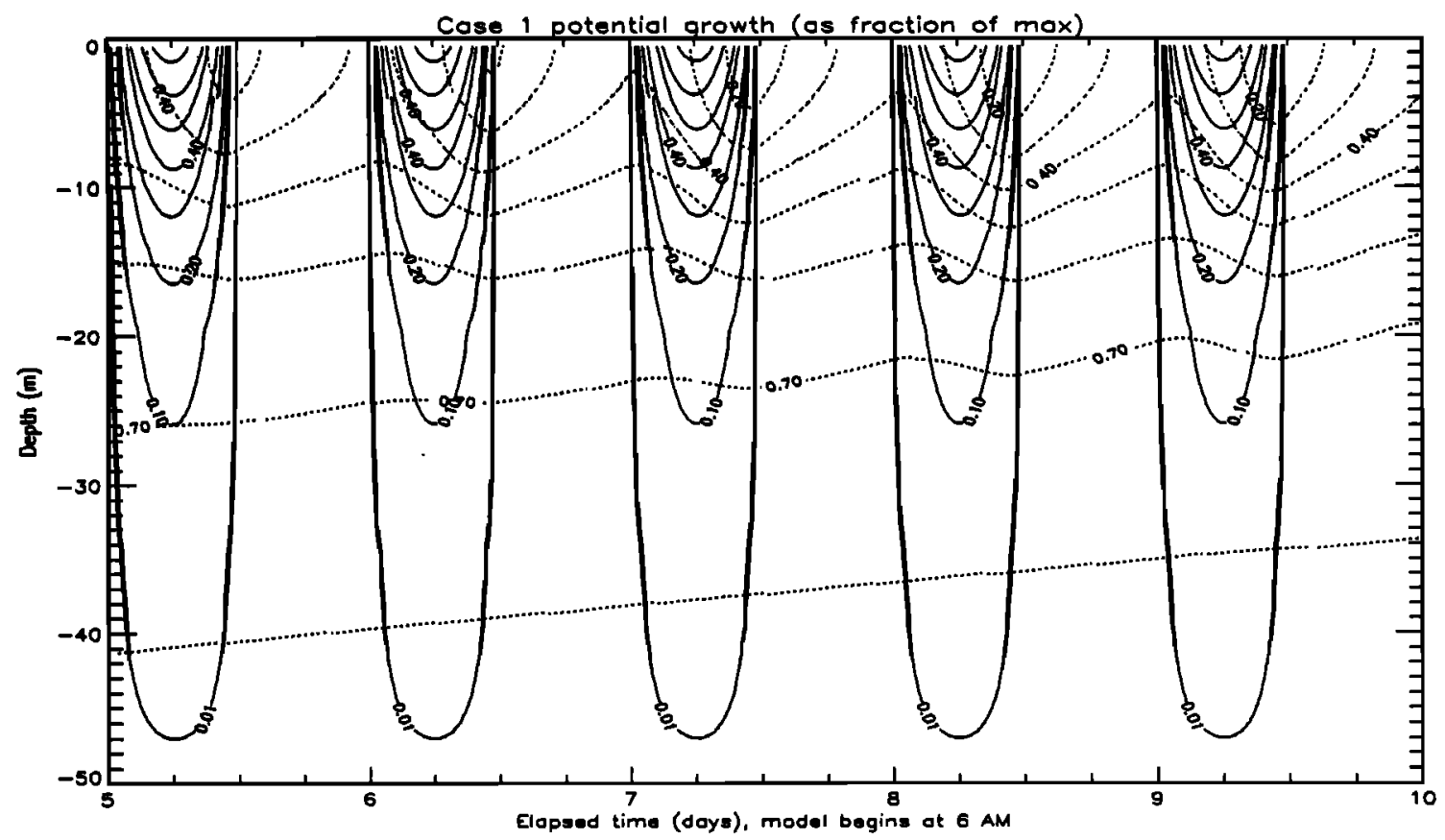

Figure 15. Potential growth as fraction of $P_{m}^{B}$ for days 6-10 of case 1: light limited (solid curve) and nitrate limited (dotted curve). 


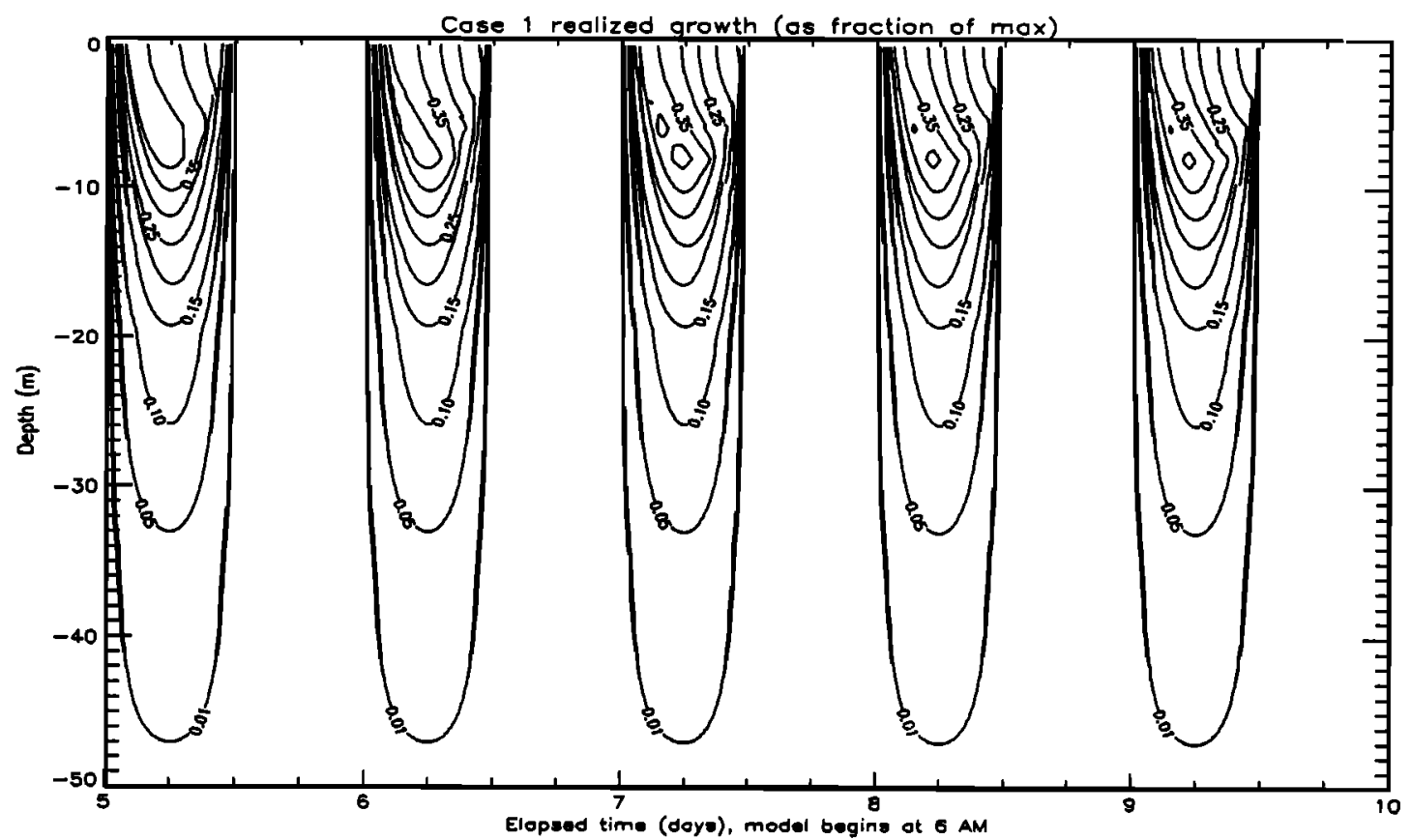

Figure 16. Realized growth as fraction of $P_{m}^{B}$ for days 6-10 of case 1, determined by the minimum at each point of the two potential rates in Figure 15.

$\mathrm{L}^{-1}$ for case 1 (see Figure 10); this is similar to the decrease from $\sim 2.5$ to $\sim 0.5 \mu \mathrm{g} \mathrm{chl} \mathrm{L}{ }^{-1}$ found by Marra and $\mathrm{Ho}$ [1993] when the maximum growth rate is decreased by half.

The depth-integrated chlorophyll of the euphotic zone is shown in Figure 19. The integrated chlorophyll initially de- creases but recovers during day 3 and continues to increase, with diurnal fluctuations, throughout the period of the model. Comparison to Figure 11 shows that the integrated chlorophyll values are much smaller in case 2 than in case 1, being almost an order of magnitude smaller by the end of the model run.

Table 3. Chlorophyll and $\mathrm{NO}_{3}-\mathrm{N}$ Concentrations and Fluxes Over 10 Days for All Cases

\begin{tabular}{|c|c|c|c|c|}
\hline & \multicolumn{2}{|c|}{ Euphotic Zone } & \multicolumn{2}{|c|}{ Aphotic Zone } \\
\hline & Chl & $\mathrm{NO}_{3}-\mathrm{N}$ & Chl & $\mathrm{NO}_{3}-\mathrm{N}$ \\
\hline \multicolumn{5}{|c|}{ Initial Concentration, $\mathrm{mg} \mathrm{m}^{-2}$} \\
\hline & 4.605171 & 64.47238 & 0.0 & $122,737.2$ \\
\hline \multicolumn{5}{|c|}{ Final Concentration $\mathrm{mg} \mathrm{m}^{-2}$} \\
\hline 1 & 50.72236 & 2705.657 & 0.43846 & $158,849.7$ \\
\hline 2 & 5.258351 & 3019.276 & 0.03169 & $158,850.3$ \\
\hline $3 a$ & 47.32568 & 2729.958 & 0.60122 & $158,849.8$ \\
\hline $3 b$ & 51.74186 & 2697.998 & 0.34740 & $158,849.7$ \\
\hline $4 a$ & 56.97577 & 2713.683 & 0.61075 & $158,849.9$ \\
\hline $4 b$ & 46.69167 & 2707.887 & 0.33977 & $158,849.7$ \\
\hline \multicolumn{5}{|c|}{ Net Horizontal Change, $m g m^{-2}$} \\
\hline 1 & -171.1427 & $-12,752.1$ & -0.82835 & $+53,044.7$ \\
\hline 2 & -21.13812 & $-13,821.1$ & -0.22841 & $+53,044.2$ \\
\hline $3 a$ & -163.1384 & $-12,805.8$ & -0.98305 & $+53,044.7$ \\
\hline $3 b$ & -174.2224 & $-12,732.1$ & -0.74618 & $+53,044.7$ \\
\hline $4 a$ & -195.5340 & $-12,524.1$ & -1.14090 & $+53,044.2$ \\
\hline $4 b$ & -149.9591 & $-12,929.8$ & -0.62171 & $+53,044.9$ \\
\hline \multicolumn{5}{|c|}{ Vertical Exchange, $m g m^{-2}$} \\
\hline 1 & -1.266810 & $+16,932.17$ & +1.266810 & $-16,932.2$ \\
\hline 2 & -0.260105 & $+16,931.14$ & +0.260105 & $-16,931.1$ \\
\hline $3 a$ & -1.584272 & $+16,932.14$ & +1.584272 & $-16,932.1$ \\
\hline $3 \mathrm{~b}$ & -1.093577 & $+16,932.19$ & +1.093577 & $-16,932.2$ \\
\hline $4 a$ & -1.751658 & $+16,931.46$ & +1.751658 & $-16,931.5$ \\
\hline $4 \mathrm{~b}$ & -0.961487 & $+16,932.45$ & +0.961487 & $-16,932.5$ \\
\hline
\end{tabular}




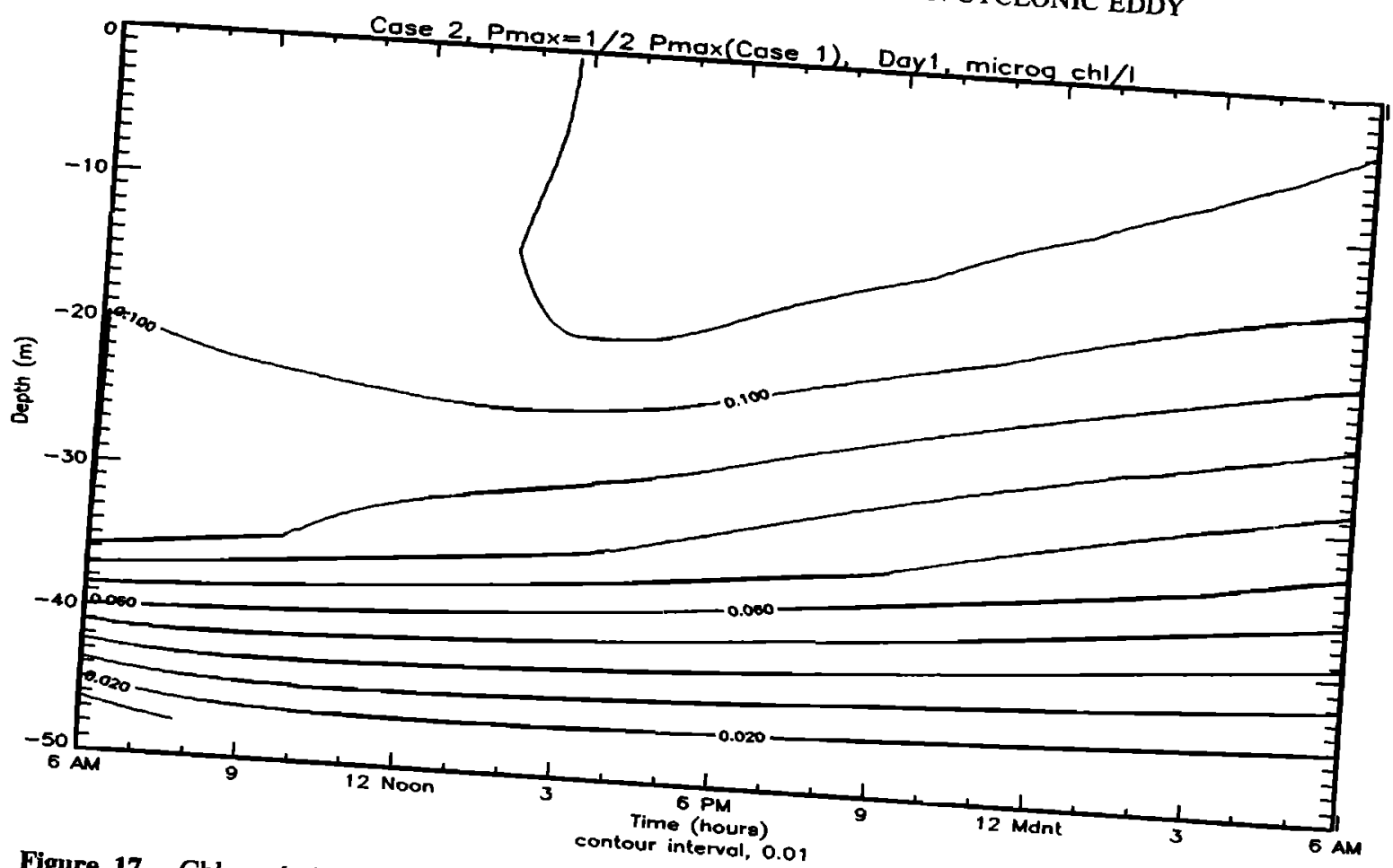

Figure 17. Chlorophyll concentrations where $P_{m}^{B}=1 / 2 \times\left(\right.$ case $\left.1 P_{m}^{B}\right)$.

Figure 19 also shows the depth-integrated nitrate for the euphotic zone. After day 3 , the integrated nitrate level
increases linearly, and there is such as exists for case 1 (see Figure 11 ). productivity of the euphotic Figure 11). Integrated primary

steadily through the 10 days of the model, reaching a
maximum of $0.2 \mathrm{~g} \mathrm{C} \mathrm{m}^{-2} \mathrm{~d}^{-1}$. maximum from case 1 (see The average integrated primary 12 ) of $2.7 \mathrm{~g} \mathrm{C} \mathrm{m}^{-2} \mathrm{~d}^{-1}$. $\mathrm{g} \mathrm{C} \mathrm{m} \mathrm{m}^{-2}$, compared to $0.87 \mathrm{~g}^{-1} \mathrm{C}^{-2} \mathrm{~d}^{-1}$ case 2 is 0.09

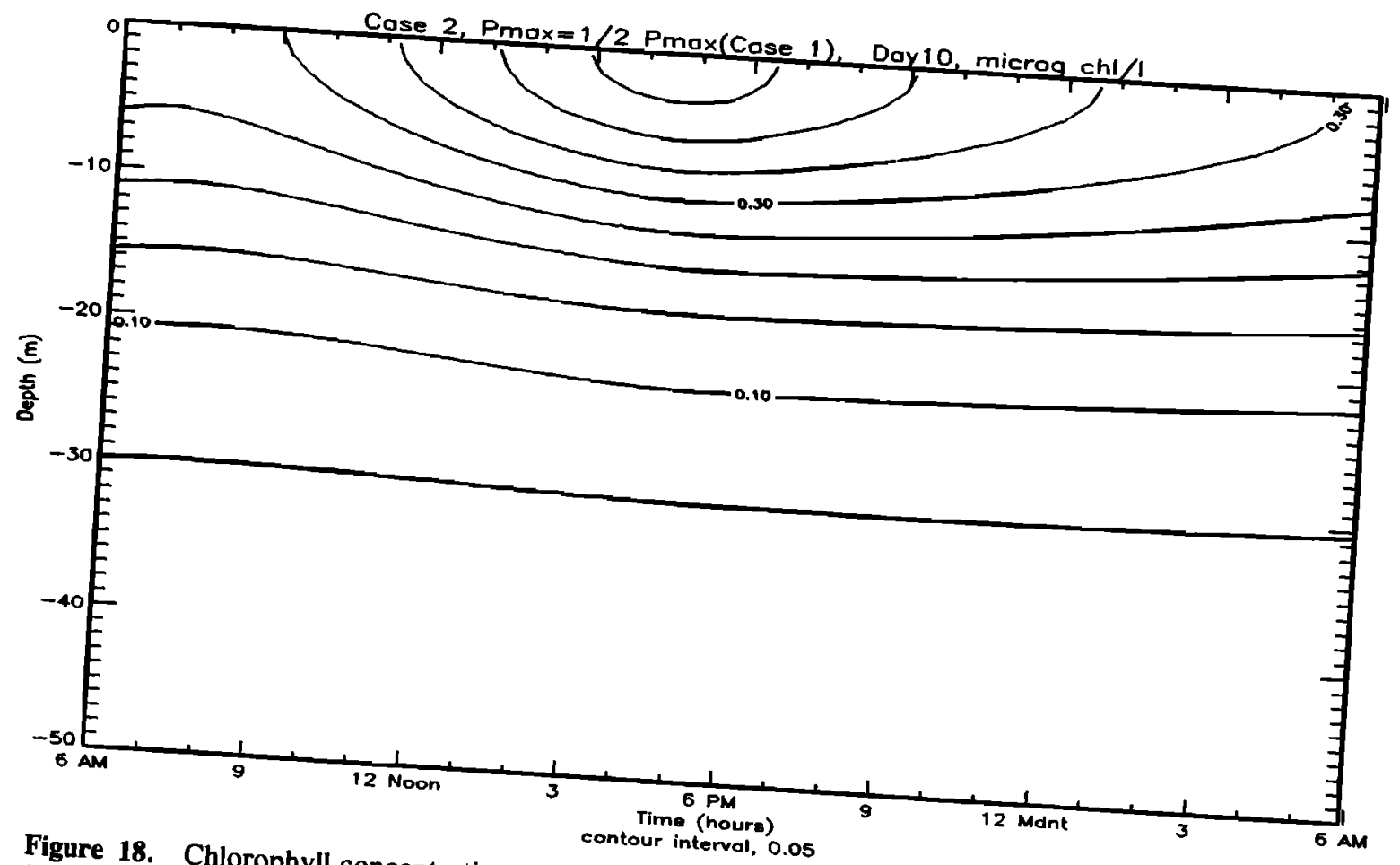

Figure 18. Chlorophyll concentrations (microst interval, 0.05

2, where $P_{m}^{B}=1 / 2 \times\left(\right.$ case $\left.1 P_{m}^{B}\right)$. 


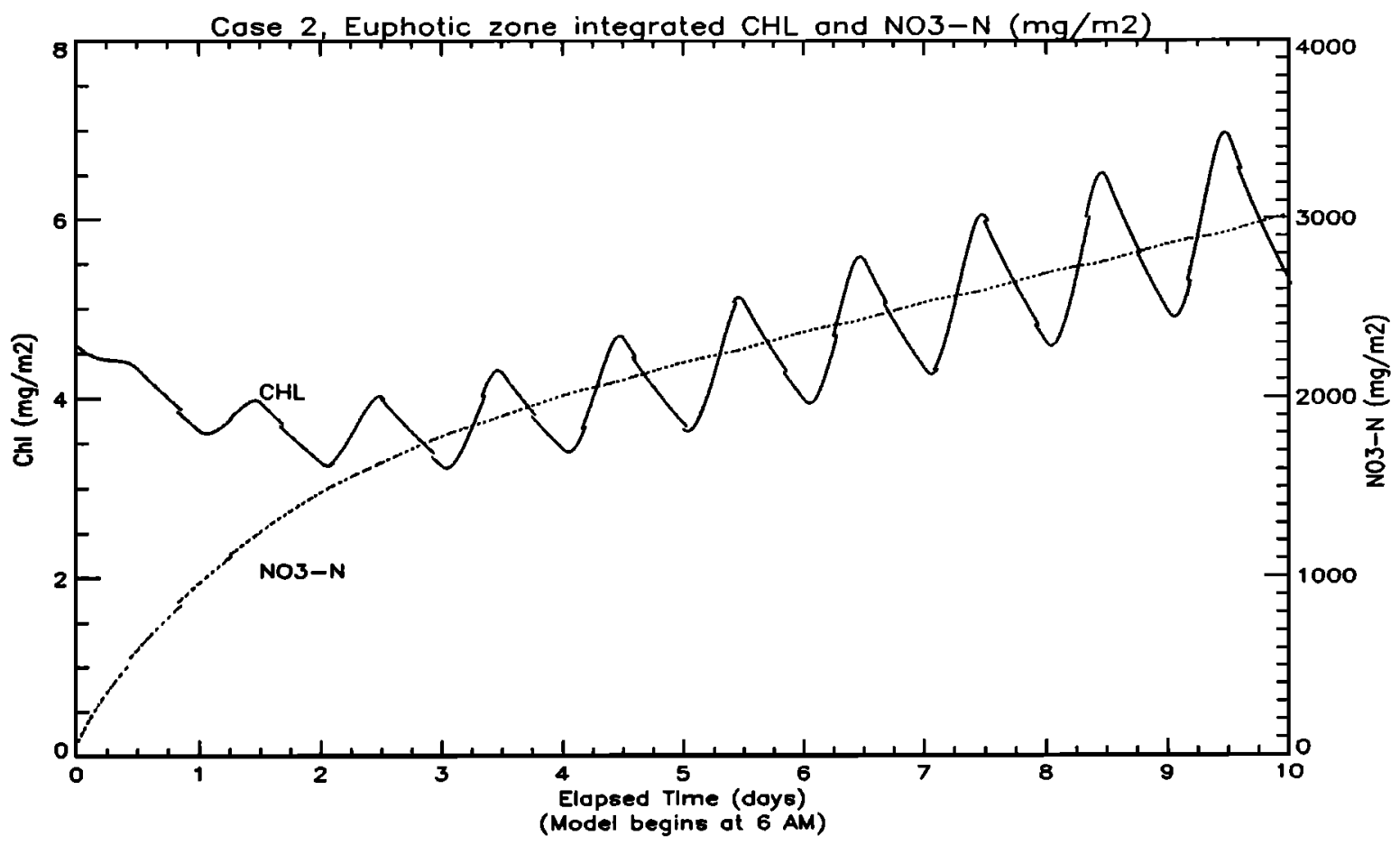

Figure 19. Euphotic zone integrated chlorophyll (milligrams per square meter; solid curve) and integrated nitrate-nitrogen (milligrams per square meter; dotted curve) over 10 days of case 2, where $P_{m}^{B}=1 / 2 \times\left(\right.$ case $\left.1 P_{m}^{B}\right)$, calculated at each time step.

Fluxes of nitrate and chlorophyll for case 2 are shown in Table 3. About $0.9 \%$ of the nitrate imported into the euphotic zone is converted into particulate nitrogen, $81.6 \%$ is lost horizontally, and $17.5 \%$ remains in the euphotic zone at the end of the model run. The vertical sinking loss of algal biomass over the 10 days of the model is $1.2 \%$ of the chlorophyll synthesized, while horizontal losses account for 95.9\%, with the remaining $2.9 \%$ left in the euphotic zone.

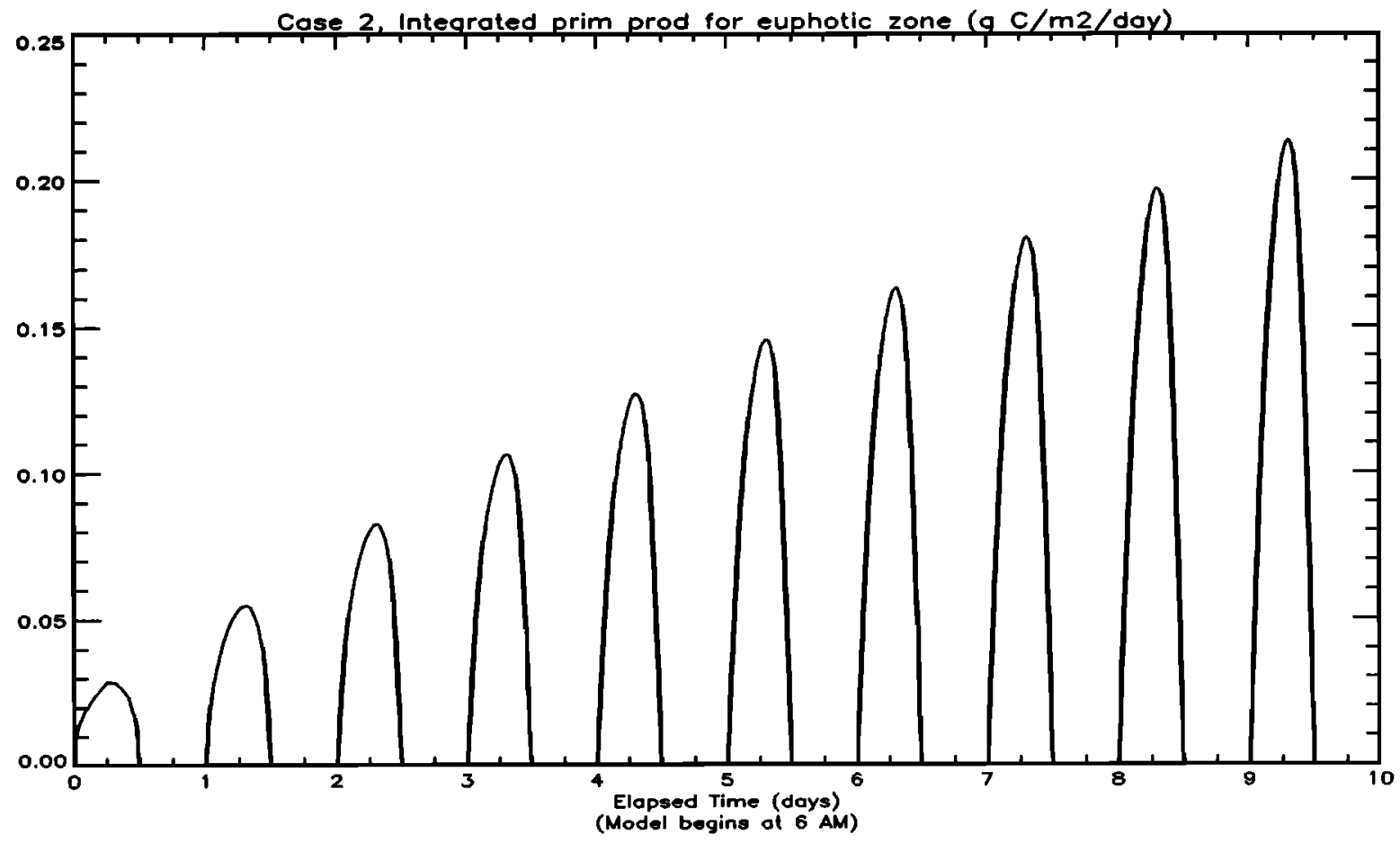

Figure 20. Euphotic zone integrated primary productivity (grams C per square meter per day) for 10 days of case 2 , where $P_{m}^{B}=1 / 2 \times\left(\right.$ case $1 P_{m}^{B}$ ), calculated at each time step. 
Case 3 (Case 3a, $\lambda=2.0$; Case 3b, $\lambda=0.5$ )

To examine the effects of the sinking parameterization, the coefficient of sinking $\lambda$ is doubled (case $3 a$ ) and halved (case $3 b)$. These changes have little effect on the potential and realized growth rates as percentages of $P_{m}^{B}$ shown for case 1 (see Figures 13, 14, 15, and 16). A small but significant difference in the chlorophyll field results, with the maximum chlorophyll concentration for day 10 of case $3 \mathrm{a}(2.9 \mu \mathrm{g}$ chl $\left.\mathrm{L}^{-1}\right)$ being $84.1 \%$ of the case 1 maximum $\left(3.5 \mu \mathrm{g} \mathrm{chl} \mathrm{L}^{-1}\right.$ (see Figure 10)) for the same day. Interestingly, the depth of the maximum during day 10 is the same for case $3 a$ and case 1 , that is, 9.16-12.04 m.

As should be expected, case $3 b$, with its decreased sinking coefficient, results in a higher maximum chlorophyll value than does case 1 , that is, $3.8 \mu \mathrm{g}$ chl L $\mathrm{L}^{-1}$ on day 10 , or $111 \%$ of the case 1 value. The case $3 \mathrm{~b}$ maximum occurs at a depth of 6.93-9.16 m. The difference in sinking rates leads to only slightly different values of depth-integrated chlorophyll, with case 3a resulting in a maximum value of $67.7 \mathrm{mg} \mathrm{m}^{-2}$ and case $3 b$ yielding $74.1 \mathrm{mg} \mathrm{m}^{-2}$. Similar effects occur in the simulated primary productivity of these runs. Maximum primary productivity for case $3 a$ is $2.6 \mathrm{~g} \mathrm{C} \mathrm{m}^{-2} \mathrm{~d}^{-1}$ compared to $2.8 \mathrm{~g} \mathrm{C} \mathrm{m}^{-2} \mathrm{~d}^{-1}$ for case $3 \mathrm{~b}$ and $2.7 \mathrm{~g} \mathrm{C} \mathrm{m}^{-2} \mathrm{~d}^{-1}$ for case 1.

Table 3 shows that for case $3 a$, at the end of the model, $20.6 \%$ of the particulate nitrogen produced from the upwelled nitrate remains in the euphotic zone, $78.6 \%$ has been lost horizontally, and $0.8 \%$ has sunk out. The phytoplankton have utilized $8.6 \%$ of the upwelled nitrate, compared to $9.1 \%$ from case 1 . In case $3 \mathrm{~b}, 21.2 \%$ of the synthesized chlorophyll is in the euphotic zone of the model after 10 days, $78.3 \%$ is lost horizontally, and only $0.5 \%$ is lost to sinking, while the phytoplankton have used $8.6 \%$ of the upwelled nitrate. Case 3a has a sinking loss which amounts to $125 \%$ of that of case 1 , compared to $86 \%$ for case $3 b$.

Case 4 (Case 4a, $P_{o}, N_{o}=2 \times P_{i}, N_{\text {init }}$; Case 4b, $P_{o}$, $N_{o}=1 / 2 \times P_{i}, N_{\text {init }} ;$ in Euphotic Zone)

Boundary conditions for case 1 equate initial chlorophyll and nitrate fields in the euphotic zone of the model to those outside the eddy. Case 4 examines the effect of varying the external chlorophyll and nitrate fields by doubling or halving those of case 1 . Case $4 a$, where the external fields are twice the internal initial fields, should be affected by a decrease in the horizontal loss term. Case $4 \mathrm{~b}$ instead sets the external fields to 0.5 the internal fields. The maximum integrated chlorophyll stock for case $4 \mathrm{a}$ is $82.5 \mathrm{mg} \mathrm{chl} \mathrm{m} \mathrm{m}^{-2}$, compared with $68.7 \mathrm{mg} \mathrm{chl} \mathrm{m}^{-2}$ for case $4 \mathrm{~b}$ and $72.6 \mathrm{mg} \mathrm{chl} \mathrm{m}^{-2}$ for case 1 . This is as expected, since case 4 a retains more chlorophyll and case $4 \mathrm{~b}$ retains less than case 1 owing to the difference in horizontal loss terms.

The vertical loss terms follow the same pattern. Case $4 \mathrm{a}$ results in $1.8 \mathrm{mg} \mathrm{chl}$ sinking out of the euphotic zone over 10 days, while case $4 \mathrm{~b}$ loses $1.0 \mathrm{mg}$ chl (see Table 3 ), compared with the case 1 loss of $1.3 \mathrm{mg}$ chl. As a result, the average primary productivity for case $4 \mathrm{a}$ is $1.0 \mathrm{~g} \mathrm{C} \mathrm{m}^{-2} \mathrm{~d}^{-1}$, since the euphotic zone retains more chlorophyll than in case 1. Case $4 \mathrm{~b}$ has a lower average primary productivity of $0.8 \mathrm{~g} \mathrm{C}$ $\mathrm{m}^{-2} \mathrm{~d}^{-1}$. The maximum integrated primary productivities from these two cases bracket that of case $1\left(2.7 \mathrm{~g} \mathrm{C} \mathrm{m}^{-2}\right.$ $\mathrm{d}^{-1}$ ), with $3.0 \mathrm{~g} \mathrm{C} \mathrm{m}^{-2} \mathrm{~d}^{-1}$ for case $4 \mathrm{a}$ and $2.6 \mathrm{~g} \mathrm{C} \mathrm{m}^{-2} \mathrm{~d}^{-1}$ for case $4 b$.
Variation in these boundary conditions yields expected changes in horizontal fluxes (see Table 3 ). The differences in nitrate fluxes between case 1 and cases $4 a$ and $4 b$ are not very large. However, the horizontal chlorophyll fluxes in the euphotic zone vary by $\sim 14 \%$ to either side of the case 1 flux. Since the depth-integrated chlorophyll stocks and carbon fixation of cases $1,3 a, 3 b, 4 a$, and $4 b$ are similar to each other but tenfold those of case 2 , we compare the case 1 results with the various data sets.

\section{Validation}

Satellite. From the satellite imagery, eddy 1 on April 13 has a northward extension to $-30.3^{\circ} \mathrm{N}$ (see Plate 1 ), which is the region our model attempts to simulate. Pigment values of the image are $\sim 0.8-1.5 \mu \mathrm{g} \mathrm{L} \mathrm{L}^{-1}$ here. Using a northward propagation speed of $35 \mathrm{~km} \mathrm{~d}^{-1}$ from $28^{\circ} \mathrm{N}$ to determine the age of the observed eddy, the eddy might be $\sim 6-7$ days old. To compare our model with the satellite data, we used the method described by Gordon and Clark [1980] to determine the "satellite-sensed" output of our model. During day 6 of the model, the chlorophyll concentration at noon, comparable to pigment concentrations sensed by satellite, is $1.38 \mu \mathrm{g}$ chl $\mathrm{L}^{-1}$. Day 7 of the model has a noon satellite-sensed value of $1.87 \mu \mathrm{g} \mathrm{chl} \mathrm{L} ~^{-1}$ (Table 4). The simulated chlorophyll concentrations in the near-surface region of the model thus match well the satellite-derived pigment values from the eddy on April 13.

The April 17 image of eddy 1 places the head of the eddy at $\sim 31.8^{\circ} \mathrm{N}$ (see Plate 2 ). Satellite-sensed pigment values in the region of interest are now $\sim 1.5-2.0 \mu \mathrm{g} \mathrm{L}^{-1}$. At this location the eddy is perhaps $\sim 10$ days old. The model for day 10 gives a satellite-sensed chlorophyll concentration of $2.53 \mu \mathrm{g} \mathrm{L}^{-1}$ at noon (Table 4). Once again the simulated phytoplankton stocks are similar to the satellite observations.

Ship. Eddy 3 (see Figure 8a, the large eddy) was not sampled in the region which this model seeks to reproduce. Yoder et al. [1981] estimate, however, that the surface $1 \mu \mathrm{g}$ $\mathrm{L}^{-1}$ isopleth extended some distance northward of the measured region. With alongshore velocities of $35 \mathrm{~km} \mathrm{~d}^{-1}$, the eddy would have been $\sim 9-10$ days old between $\sim 31.15^{\circ}$ and $\sim 31.5^{\circ} \mathrm{N}$, where the model yields surface chlorophyll concentrations of 1.5-2.4 $\mu \mathrm{g} \mathrm{L}^{-1}$ (Table 4).

Eddy 4 (see Figure 8a for the small southern chlorophyll signature of $0.5 \mu \mathrm{g} \mathrm{L}^{-1}$ ) provides a direct comparison of shipboard and simulated chlorophyll stocks by assuming that the leading region of this eddy is 3 days old; that is, it was at $29^{\circ} \mathrm{N}$ after formation at $28^{\circ} \mathrm{N}$ and propagation northward at $35 \mathrm{~km} \mathrm{~d}^{-1}$. The measured surface chlorophyll concentrations are $\sim 0.3-0.5 \mu \mathrm{g} \mathrm{L}^{-1}$ [Yoder et al., 1981], which compare favorably with the model results of $0.2 \mu \mathrm{g} \mathrm{L}^{-1}$ at $0600 \mathrm{LT}$ and $0.4 \mu \mathrm{g} \mathrm{L}^{-1}$ at $1800 \mathrm{LT}$ on day 3 of the simulation (Table 4).

The age of eddy 4 upon its arrival near stations occupied at $30.5^{\circ} \mathrm{N}$ is estimated to be $\sim 7$ days. The model yields a depth-integrated primary production of $0.9 \mathrm{~g} \mathrm{C} \mathrm{m}^{-2} \mathrm{~d}^{-1}$ after day 6 (ending at $0600 \mathrm{LT}$ ) that increases to $1.2 \mathrm{~g} \mathrm{C} \mathrm{m}^{-2}$ $\mathrm{d}^{-1}$ by $1800 \mathrm{LT}$ on day 7; by way of comparison, Yoder et al. [1983] measured a primary productivity of $\sim 1.1 \mathrm{~g} \mathrm{C} \mathrm{m}^{-2} \mathrm{~d}^{-1}$ for eddy 4 at $30.5^{\circ} \mathrm{N}$ on April 27, 1979 (see Figure 8t and Table 4). It should be noted, however, that the eddy was assumed to be approximately 3 days old when measured over April 20-22 so that by April 27 the eddy would be 
Table 4. Comparison of Measured Data With Model Results

\begin{tabular}{|c|c|c|c|c|c|c|}
\hline \multirow[b]{2}{*}{ Source } & \multirow[b]{2}{*}{$\begin{array}{l}\text { Eddy } \\
\text { Number }\end{array}$} & \multicolumn{3}{|c|}{ Measured Data } & \multicolumn{2}{|c|}{ Case 1 Results } \\
\hline & & $\begin{array}{c}\text { Northern } \\
\text { Extent }\end{array}$ & $\begin{array}{c}\text { Approximate } \\
\text { Eddy Age, days }\end{array}$ & Data & $\begin{array}{c}\text { Eddy Age, } \\
\text { days }\end{array}$ & Data \\
\hline Satellite, April 13 & 1 & $30.3^{\circ} \mathrm{N}$ & $6-7$ & $0.75-1.5 \mu \mathrm{g} \mathrm{chl} \mathrm{L}-1$ & $6-7$ & $\underset{\text { (noon) }}{1.38-1.87 \mu \mathrm{g} \mathrm{chl} \mathrm{L}} \mathrm{L}^{-1}$ \\
\hline Satellite, April 17 & 1 & $31.8^{\circ} \mathrm{N}$ & 10 & $1.5-2.0 \mu \mathrm{g} \mathrm{chl} \mathrm{L}^{-1}$ & 10 & $\begin{array}{l}2.53 \mu \mathrm{g} \text { chl L } \\
\text { (noon) }\end{array}$ \\
\hline $\begin{array}{l}\text { Shipboard data (est), } \\
\text { April } 22\end{array}$ & 3 & $\begin{array}{l}\sim 31.15^{\circ} \mathrm{N} \\
-\sim 31.5^{\circ} \mathrm{N}\end{array}$ & $9-10$ & $\begin{array}{l}\sim 1 \mu \mathrm{g} \mathrm{chl} \mathrm{L}^{-1} \\
\text { (surface) }\end{array}$ & $9-10$ & $1.5-2.4 \mu \mathrm{g} \mathrm{chl} \mathrm{L} \mathrm{L}^{-1}$ \\
\hline $\begin{array}{l}\text { Shipboard data, April } \\
20-22\end{array}$ & 4 & $29^{\circ} \mathrm{N}$ & 3 & $\begin{array}{l}0.3-0.5 \mu \mathrm{g} \mathrm{chl} \mathrm{L}{ }^{-1} \\
\text { (surface) }\end{array}$ & 3 & $\begin{array}{l}0.2-0.4 \mu \mathrm{g} \mathrm{chl} \mathrm{L} \mathrm{L}^{-1} \\
(0600-1800 \mathrm{LT})\end{array}$ \\
\hline $\begin{array}{l}\text { Production station, } \\
\text { April } 27\end{array}$ & 4 & $30.5^{\circ} \mathrm{N}$ & 7 & $\begin{array}{l}1.1 \mathrm{~g} \mathrm{C} \mathrm{m}^{-2} \mathrm{~d}^{-1} \\
2 \times 10^{-2} \mathrm{~g} \mathrm{chl} \mathrm{m}^{-2} \\
2.1 \mathrm{~g} \mathrm{NO}_{3}-\mathrm{N} \mathrm{m}^{-2}\end{array}$ & 7 & $\begin{array}{l}0.9-1.2 \mathrm{~g} \mathrm{C} \mathrm{m}^{-2} \mathrm{~d}^{-1} \\
2.0 \times 10^{-2}-2.9 \times 10^{-2} \\
\mathrm{~g} \mathrm{chl} \mathrm{m}^{-2} \\
2.25-2.35 \mathrm{~g} \mathrm{NO}_{3}-\mathrm{N} \\
\mathrm{m}^{-2}\end{array}$ \\
\hline
\end{tabular}

Est, estimated.

-8-10 days old; a storm had halted sampling on April 25 and 26 [Yoder et al., 1983], with unknown consequences for the chlorophyll and nitrate signatures of the eddy. A peak in nitrate in the euphotic zone was observed on April 27 and was followed the next day by a peak in chlorophyll (see Figure 8b), which would be consistent with an upwelling center leading the higher chlorophyll signature through the study site.

Measurements of nitrate and chlorophyll stocks taken from eddy 4 at $30.5^{\circ} \mathrm{N}$ on April 27 can also be compared to the model. The integrated chlorophyll of the modeled euphotic zone ranges from $2.02 \times 10^{-2}$ to $2.86 \times 10^{-2} \mathrm{~g} \mathrm{~m}^{-2}$ on day 7 and compares favorably with the measured value of $-2 \times 10^{-2} \mathrm{~g} \mathrm{chl} \mathrm{m}^{-2}$ (see Figure 8b, April 27, and Table 4). Modeled nitrate concentrations over the euphotic zone range from 2.25 to $2.35 \mathrm{~g} \mathrm{NO}_{3}-\mathrm{N} \mathrm{m}^{-2}$ over the same period and also approximate the measured value of $\sim 2.1 \mathrm{~g} \mathrm{NO}_{3}-\mathrm{N} \mathrm{m}^{-2}$ (see Figure 8b, April 27, and Table 4).

If one decomposes the depth integrals into vertical distributions of nitrate and chlorophyll, however, some of the model's fidelity to the real world is lost. The nutricline, where nitrate concentrations increase from near 0.0 to $\sim 5$ $\mu M$ within a depth range of 10 to $15 \mathrm{~m}$, begins at $\sim 15 \mathrm{~m}$ in the sea (see Figure 8c, April 27); the model nutricline is not as sharply defined by days 7 and 8 , which bracket the assumed age of the eddy upon reaching $30.5^{\circ} \mathrm{N}$ on April 27. The model results in $\mathrm{NO}_{3}$ concentrations ranging in an almost linear manner from $\sim 1.0 \mu M$ at the surface to $\sim 9 \mu M$ at $\sim 50 \mathrm{~m}$. This discrepancy may be attributable to mixing caused by the storm of April 25 and 26 or to differences in the real and simulated upwelling velocities.

The measured vertical distribution of chlorophyll is likewise not reproduced as well by the model. The modeled chlorophyll profile has maxima near the surface of $1.1 \mu \mathrm{g} \mathrm{chl}$ $\mathrm{L}^{-1}$ at the beginning of day 7 and $1.4 \mu \mathrm{g} \mathrm{chl} \mathrm{L}^{-1}$ by the end of the dark period; the simulated subsurface phytoplankton biomass decreases to $\sim 10 \%$ of the maximum at $25 \mathrm{~m}$. This is in contrast to the more uniform chlorophyll distribution of $\sim 1.0 \mu \mathrm{g} \mathrm{chl} \mathrm{L}{ }^{-1}$ measured after the storm (see Figure 8c, April 27). The fact that the modeled column is taken at the center of the upwelling field, whereas the measured data are inshore of the eddy center located approximately over the 200-m isobath [Yoder et al., 1983] may also contribute to this discrepancy. However, as the particular location of the measurements in relation to the eddy center is uncertain, this is the only comparison to be made.

\section{Discussion}

This model, while simulating certain observed data to a degree, does have its problems. The physical model does not incorporate realistic bottom topography, such as the divergence of isobaths north of Cape Canaveral, which has an effect on the flow field [Blanton et al., 1981]. The physical model also overestimates transport through the domain, the formulation for this, as mentioned previously, being chosen to match that observed farther north, resulting in an unrealistic temperature field and thus an unrealistic nitrate field, leading to (6). The modeled eddy is also farther offshore than is observed.

The biological model has, by the assumptions used in its construction, inherently neglected any algal groups other than diatoms and the associated different nitrate utilization rates of these ignored assemblages. However, because of the preponderance of diatoms in the algal samples taken, this was seen as a justifiable omission. The biological model also uses the divergence of the vertical flow field to estimate horizontal losses and thus neglects diffusive losses from the domain.

Comparison with gathered data and satellite images also depends upon estimations of the speed and thus the age of the modeled eddy and of the location within the eddy with which we compare our modeled column. This is especially apparent when comparing the vertical profiles with those measured: the modeled profiles were over the $800-\mathrm{m}$ isobath, whereas those measured were inshore of the $100-\mathrm{m}$ isobath.

Case 1 of our simple, quasi-one-dimensional model provides a reasonably good match to data obtained from both the satellite overpasses and shipboard measurements. The poor fidelity of case 2 also supports our reasoning for a single limiting factor (rather than multiplicative factors) for the assessment of the primary production of successional stages 
of the phytoplankton community. The case 3 and case 4 results attest to the robustness of the model under various sinking parameterizations and boundary conditions for the upwelled center of a cyclonic eddy.

As one proceeds away from the upwelled center, other factors become operative, however. Yoder [1985] noted that the species compositions of eddies south of the Charleston Bump may be related to the coastal phytoplankton assemblage. The image of April 13, 1979 (Plate 1), appears to show a connection between the chlorophyll field of the shelf and that of eddy 1 such that eddies within the southern half of the SAB may be seeded laterally by coastal phytoplankton populations. It should also be noted, however, that this apparent connection may result from onshore flow of eddy phytoplankton if the flow field is as envisioned by Pietrafesa et al. [1985].

Similarly, the variation in the sinking rates did not provide large differences in vertical carbon fluxes within a region of positive vertical velocity. The downwelling center at the southern end of the eddy (see Figure 2), however, may act as a conduit of particulate carbon and nitrogen as well as of unutilized nitrate to bottom waters and the slope sediment. This mechanism may be partly responsible for both high carbon fluxes trapped at depths greater than $1000 \mathrm{~m}$ [Hinga et al., 1979] and the $>1 \%$ dry weight carbon concentration found within SAB slope sediments [Hathaway, 1971].

The results of our quasi-one-dimensional time-dependent biological model suggest that the new production at the head of a cyclonic eddy may be equivalent to the total primary production of this area. Understanding what fraction of the primary production over an entire eddy is new production and the amounts and fates of the nitrogen and carbon fluxes requires an extension of this model to all four $(x, y, z, t)$ dimensions. A three-dimensional, time-dependent biological model coupled to the existing physical model would certainly provide a better understanding of (1) the ecological consequences of the trailing downwelling region of an eddy and (2) the importance of horizontal boundary conditions at the shelf edge. However, since validation data in the vertical dimension are rare compared to satellite assessments of surface features, we chose to begin at the eddy center.

As a means of understanding the dynamics of just the upwelling component of the ecosystem, our two-dimensional $(z, t)$ calculation is sufficient to give an idea of the relative importance of various processes; away from the eddy center, where physical factors predominate, we expect the biological processes to become more effective.

Acknowledgments. We wish to express our thanks to Mark Meyers and Herschel Hochman for their assistance and advice over the period of this work. This research was supported by the National Aeronautics and Space Administration under grant NAGW-678.

\section{References}

Alldredge, A. L., and C. C. Gotschalk, Direct observations of the mass flocculation of diatom blooms: Characteristics, settling velocities, and formation of the diatom aggregates, Deep Sea Res., 36, 159-171, 1989.

Atkinson, L. P., Hydrography and nutrients of the southeastern U.S. continental shelf, in Oceanography of the Southeastern U.S. Continental Shelf, Coastal Estuarine Sci., vol. 2, edited by L. P. Atkinson, D. W. Menzel, and K. A. Bush, pp. 77-92, AGU, Washington, D. C., 1985.

Atkinson, L. P., and D. W. Menzel, Introduction: Oceanography of the southeast United States continental shelf, in Oceanography of the Southeastern U.S. Continental Shelf, Coastal Estuarine Sci., vol. 2, edited by L. P. Atkinson, D. W. Menzel, and K. A. Bush, pp. 1-9, AGU, Washington, D. C., 1985.

Atkinson, L. P., G.-A. Paffenhofer, and W. M. Dunstan, The chemical and biological effect of a Gulf Stream intrusion off St. Augustine, Florida, Bull. Mar. Sci., 11, 359-368, 1978.

Atkinson, L. P., L. J. Pietrafesa, and E. E. Hofmann, An evaluation of nutrient sources to Onslow Bay, North Carolina, J. Mar. Res., 40, 679-699, 1982.

Atkinson, L. P., T. N. Lee, J. O. Blanton, and W. S. Chandler, Climatology of southeastern United States shelf waters, J. Geophys. Res., 88, 4705-4718, 1983.

Atkinson, L. P., P. G. O'Malley, J. A. Yoder, and G.-A. Paffenhofer, The effect of summertime shelf break upwelling on nutrient flux in southeastern United States continental shelf waters, $J$. Mar. Res., 42, 969-993, 1984.

Bane, J. M., Jr., and D. A. Brooks, Gulf Stream meanders along the continental margin from the Florida Straits to Cape Hatteras, Geophys. Res. Lett., 6, 280-282, 1979.

Bishop, S. S., J. A. Yoder, and G.-A. Paffenhofer, Phytoplankton and nutrient variability along a cross-shelf transect off Savannah, Georgia, USA, Estuarine Coastal Mar. Sci., 11, 359-368, 1980.

Blackman, F. F., Optima and limiting factors, Ann. Bot., 19, 281-295, 1905.

Blanton, J. O., L. P. Atkinson, L. J. Pietrafesa, and T. N. Lee, The intrusion of Gulf Stream water across the continental shelf due to topographically-induced upwelling, Deep Sea Res., Part A, 28, 393-405, 1981.

Bryan, K., A numerical method for the study of the circulation of the world ocean, J. Comput. Phys., 4, 347-376, 1969.

Cox, M. D., A primitive equation, 3-dimensional model of the ocean, Ocean Group Tech. Rep. 1, 143 pp., Geophys. Fluid Dyn. Lab., Princeton, N. J., 1984.

Deibel, D., Laboratory determined mortality, fecundity and growth rates of Thalia democratica Forskal and Dolioletta gegenbauri Uljanin (Tunicata, Thaliacea), J. Plankton Res., 4, 143-153, 1982.

Eppley, R. W., Temperature and phytoplankton growth in the sea, Fish. Bull., 70, 1063-1085, 1972.

Franks, P. J. S., J. S. Wroblewski, and G. R. Flierl, Prediction of phytoplankton growth in response to the frictional decay of a warm-core ring, J. Geophys. Res., 91, 7603-7610, 1986.

Goldman, J. C., and E. J. Carpenter, A kinetic approach to the effect of temperature on algal growth, Limnol. Oceanogr., 19, 756-766, 1974.

Gordon, H. R., and D. K. Clark, Remote sensing optical properties of a stratified ocean: An improved interpretation, Appl. Opt., 19, 3428-3430, 1980.

Gregg, W. W., and J. J. Walsh, Simulation of the 1979 spring bloom in the Mid-Atlantic Bight: A coupled physical/biological/optical model, J. Geophys. Res., 97, 5723-5743, 1992.

Hathaway, J. C., WHOI data file, continental margin program, Atlantic coast of the United States, Tech. Rep. WHOI-77-15, 259 pp., Woods Hole Oceanogr. Inst., Woods Hole, Mass., 1971.

Heinbokel, J. F., Studies on the functional role of tintinnids in the Southern California Bight, I, Grazing and growth rates in laboratory cultures, Mar. Biol., 47, 177-189, 1978.

Hinga, K. R., J. M. Sieburth, and G. R. Heath, The supply and use of organic material at the deep-sea floor, J. Mar. Res., 37, 557-579, 1979.

Hofmann, E. E., Plankton dynamics on the outer southeastern U.S. continental shelf, III, A coupled physical-biological model, $J$. Mar. Res., 46, 919-946, 1988.

Hofmann, E. E., and J. W. Ambler, Plankton dynamics on the outer southeastern U.S. continental shelf, II, A time-dependent biological model, J. Mar. Res., 46, 883-917, 1988.

Howard, K. M., and I. R. Joint, Physiological ecology of picoplankton in the North Sea, Mar. Biol., 102, 275-281, 1989.

Ishizaka, J., Coupling of coastal zone color scanner data to a physical-biological model of the southeastern U.S. continertal shelf ecosystem, 1, CZCS data description and Lagrangian particle tracing experiments, J. Geophys. Res., 95, 20,167-20,181, 1990a.

Ishizaka, J., Coupling of coastal zone color scanner data to a physical-biological model of the southeastern U.S. continental 
shelf ecosystem, 2, An Eulerian model, J. Geophys. Res., 95, 20,183-20,199, 1990b.

Ishizaka, J., Coupling of coastal zone color scanner data to a physical-biological model of the southeastern U.S. continental shelf ecosystem, 3, Nutrient and phytoplankton fluxes and CZCS data assimilation, J. Geophys. Res., 95, 20,201-20,212, 1990c.

Ishizaka, J., and E. E. Hofmann, Plankton dynamics on the outer southeastern U.S. continental shelf, I, Lagrangian particle tracing experiments, J. Mar. Res., 46, 853-882, 1988.

Jassby, A. D., and T. Platt, Mathematical formulation of the relationship between photosynthesis and light for phytoplankton, Limnol. Oceanogr., 21, 540-547, 1976.

Knauss, J. A., A note on the transport of the Gulf Stream, Deep Sea Res., 16, suppl., 117-123, 1969.

Lee, T. N., and D. Mayer, Low frequency current variability and spin-off eddies on the shelf off southeast Florida, J. Mar. Res., 35, 193-220, 1977.

Lee, T. N., L. P. Atkinson, and R. Legeckis, Observations of a Gulf Stream frontal eddy on the Georgia continental shelf, April, 1977, Deep Sea Res., 28, 347-378, 1981.

Lee, T. N., V. Kourafalou, J. D. Wang, W. J. Ho, J. O. Blanton, L. P. Atkinson, and L. J. Pietrafesa, Shelf circulation from Cape Canaveral to Cape Fear during winter, in Oceanography of the Southeastern U.S. Continental Shelf, Coastal Estuarine Sci., vol. 2, edited by L. P. Atkinson, D. W. Menzel, and K. A. Bush, pp. 33-62, AGU, Washington, D. C., 1985.

Lee, T. N., J. A. Yoder, and L. P. Atkinson, Gulf Stream frontal eddy influence on productivity of the southeast U.S. continental shelf, J. Geophys. Res., 96, 22,191-22,205, 1991.

Legeckis, R., Satellite observations of the influence of bottom topography on the seaward deflection of the Gulf Stream off Charleston, South Carolina, J. Phys. Oceanogr., 9, 483-497, 1979.

Liebig, J., Chemistry in Its Application to Agriculture and Physiology, 4th ed., 352 pp., Taylor \& Walton, London, 1847.

Luther, M. E., and J. M. Bane, Mixed instabilities in the Gulf Stream over the continental slope, J. Phys. Oceanogr., 15, 3-23, 1985.

Marra, J., and C. Ho, Initiation of the spring bloom in the northeast Atlantic $\left(47^{\circ} \mathrm{N}, 20^{\circ} \mathrm{W}\right)$ : A numerical simulation, Deep Sea Res., Part II, 40(1/2), 55-73, 1993.

Mellor, G. L., L. H. Kantha, and H. J. Herring, On Gulf Stream frontal eddies: A numerical experiment, Ocean Modell. 68, pp. 7-11, Hooke Inst., Oxford Univ., Oxford, England, 1986.

Müller-Karger, F. E., C. R. McClain, J. R. Fisher, W. E. Esaias, and R. Varela, Pigment distribution in the Caribbean Sea: Observations from space, Prog. Oceanogr., 23, 23-64, 1989.

Oey, L. Y., A model of Gulf Stream frontal instabilities, meanders, and eddies along the continental slope, J. Phys. Oceanogr., 18, 211-229, 1988.

Orlanski, I., A simple boundary condition for unbounded hyperbolic flows, J. Comput. Phys., 21, 251-269, 1976.

Orlanski, I., and M. D. Cox, Baroclinic instability in ocean currents, Geophys. Fluid Dyn., 4, 297-332, 1973.

Pietrafesa, L. J., G. S. Janowitz, and P. A. Wittman, Physical oceanographic processes in the Carolina Capes, in Oceanography of the Southeastern U.S. Continental Shelf, Coastal Estuarine Sci., vol. 2, edited by L. P. Atkinson, D. W. Menzel, and K. A. Bush, pp. 23-32, AGU, Washington, D. C., 1985.

Platt, T., S. Sathyendranath, and P. Ravindram, Primary production by phytoplankton: Analytic solutions for daily rates per unit area of water surface, Proc. R. Soc. London, Ser. B, 24I, 101-111, 1990.

Redfield, A. C., B. H. Ketchum, and F. A. Richards, The influence of organisms on the composition of seawater, in The Sea, vol. 2, edited by M. N. Hill, pp. 26-77, Wiley-Interscience, New York, 1963.

Rhee, G.-Y., and I. J. Gotham, The effect of environmental factors on phytoplankton growth: Temperature and the interactions of temperature with nutrient limitation, Limnol. Oceanogr., 26, $635-648,1981$.

Rhee, G.-Y., and I. J. Gotham, The effect of environmental factors on phytoplankton growth: Light and the interactions of light with nitrate limitation, Limnol. Oceanogr., 26, 649-659, 1981 b.

Richardson, W. S., W. J. Schmitz, Jr., and P. P. Niiler, The velocity structure of the Florida Current from the Straits of Florida to Cape Fear, Deep Sea Res., 16, suppl., 225-231, 1969.

Riebesell, U., Particle aggregation during a spring bloom, I, Physical aspects, Mar. Ecol. Prog. Ser., 69, 273-280, 1991.

Sathyendranath, S., T. Platt, E. P. W. Horne, W. C. Harrison, O. Ulloa, R. Outerbridge, and N. Hoepffner, Estimation of new production in the ocean by compound remote sensing, Nature, 353, 129-133, 1991.

Singer, J. J., L. P. Atkinson, J. O. Blanton, and J. A. Yoder, Cape Romain and the Charleston Bump: Historical and recent hydrographic observations, J. Geophys. Res., 88, 4685-4697, 1983.

Smolarkiewicz, P. K., A simple positive definite advection scheme with small implicit diffusion, Mon. Weather Rev., Ill, 479-486, 1983.

Tilman, D., M. Mattson, and S. Langer, Competition and nutrient kinetics along a temperature gradient: An experimental test of a mechanistic approach to niche theory, Limnol. Oceanogr., 26, 1020-1033, 1981 .

Verity, P. G., Grazing, respiration, excretion, and growth rates of tintinnids, Limnol. Oceanogr., 30, 1268-1282, 1985.

Vukovich, F. M., B. W. Crissman, M. Buchnell, and W. J. King, Gulf Stream boundary eddies off the east coast of Florida, $J$. Phys. Oceanogr., 9, 1214-1222, 1979.

Walsh, J. J., On the Nature of Continental Shelves, 520 pp., Academic, San Diego, Calif., 1988.

Walsh, J. J., D. A. Dieterle, and M. B. Meyers, A simulation analysis of the fate of phytoplankton within the Mid-Atlantic Bight, Cont. Shelf Res., 8, 757-787, 1988.

Walsh, J. J., D. A. Dieterle, M. B. Meyers, and F. E. MüllerKarger, Nitrogen exchange at the continental margin: A numerical study of the Gulf of Mexico, Prog. Oceanogr., 23, 245-301, 1989.

Walsh, J. J., K. L. Carder, and F. E. Müller-Karger, Meridional fluxes of dissolved organic matter in the North Atlantic Ocean, $J$. Geophys. Res., 97, 15,625-15,638, 1992.

Yoder, J. A., Environmental control of phytoplankton production on the southeastern U.S. continental shelf, in Oceanography of the Southeastern U.S. Continental Shelf, Coastal Estuarine Sci., vol. 2, edited by L. P. Atkinson, D. W. Menzel, and K. A. Bush, pp. 93-103, AGU, Washington, D. C., 1985.

Yoder, J. A., L. P. Atkinson, T. N. Lee, H. H. Kim, and C. R. McClain, Roles of Gulf Stream frontal eddies in forming phytoplankton patches on the outer southeastern shelf, Limnol. Oceanogr., 26, 1103-1110, 1981.

Yoder, J. A., L. P. Atkinson, S. S. Bishop, E. E. Hofmann, and T. N. Lee, Effect of upwelling on phytoplankton productivity of the outer southeastern United States continental shelf, Cont. Shelf Res., I, 385-404, 1983.

Yoder, J. A., L. P. Atkinson, S. S. Bishop, J. D. Blanton, T. N. Lee, and L. J. Pietrafesa, Phytoplankton dynamics within Gulf Stream intrusions on the southeastern United States continental shelf, Cont. Shelf Res., 4, 611-635, 1985.

Zantopp, R. J., K. D. Leaman, and T. N. Lee, Florida Current meanders: A close look in June-July 1984, J. Phys. Oceanogr., 17, 584-595, 1987.

D. A. Dieterle, J. R. Pribble, and J. J. Walsh, Department of Marine Science, University of South Florida, 140 Seventh Avenue South, St. Petersburg, FL 33701-5016.

F. E. Müller-Karger, NASA Headquarters, 300 E Street, S.W., Washington, DC 20546.

(Received October 31, 1992; revised October 8, 1993; accepted October 18, 1993.) 